Natural Language Semantics manuscript No.

(will be inserted by the editor)

\title{
Incomplete Descriptions and Indistinguishable Participants
}

\author{
Paul Elbourne
}

Received: date / Accepted: date

\begin{abstract}
The implicit content associated with incomplete definite descriptions is contributed in the form of definite descriptions of situations. A definite description of this kind is contributed by a small structure in the syntax, which is interpreted, in general terms, as 'the situation that bears $R$ to $s$ '. It is first argued that an analysis that has the implicit content come in via situation variables is superior to one that allows it to be of other semantic types. Then it is shown that this analysis has to be loosened in order to deal with cases of indistinguishable participants, also known as bishop sentences. The result is as described.
\end{abstract}

Keywords definite descriptions · incompleteness · implicit content · donkey anaphora $\cdot$ indistinguishable participants $\cdot$ bishop sentences $\cdot$ situation semantics

\section{Introduction}

In this article, I argue that the implicit content associated with incomplete definite descriptions (the table, and so on) is contributed in the form of definite descriptions of situations. These definite descriptions are contributed by small structures in the syntax that look like this: [THE [R s]]. These structures are interpreted, in general terms, as 'the situation that bears $R$ to $s$ '.

I will show that an analysis that has the implicit content come in via situation variables is superior to one that allows it to be of other semantic types ( $\S 6)$. This will set up a preliminary analysis that uses only situation variables for the provision of implicit content in the case of incomplete definite descriptions. Then I will show that this analysis has to be loosened slightly in order to deal with cases of donkey-anaphoric definite descriptions that involve indistinguishable participants $(\S \S 7-8)$. The result will be an analysis that uses definite descriptions of situations.

Before I embark on this argumentation, I will lay out some preliminary matters that will be helpful in order to understand it. I begin with some comments on incomplete definite descriptions $(\S 2)$ and situation variables (§3). The later argumentation

Paul Elbourne

Magdalen College

Oxford OX1 4AU

United Kingdom

E-mail: paul.elbourne@magd.ox.ac.uk 
will involve detailed calculations of the truth conditions of various sentences involving donkey-anaphoric definite descriptions. For this purpose, it will be useful to lay out a formal system $(\S 4)$ and introduce the situation-semantic analysis of donkey sentences (§5). First, though, let us turn to incomplete definite descriptions and their analysis.

\section{Incomplete Definite Descriptions}

The most widespread view of the semantics of definite descriptions (Frege 1892, Russell 1905) is that it involves there being exactly one thing that fulfills the descriptive content. For an assertion involving a definite description the so-and-so to be felicitous and true, there has to be exactly one so-and-so. This is what I will assume henceforth. ${ }^{1}$

An incomplete definite description (Quine 1940, Strawson 1950, 1954, Sellars 1954, Neale 1990, 2000, 2004, 2007, Szabó 2000, 2003, Stanley 2002, Elbourne 2008, 2013) is one whose overt descriptive content is applicable to more than one thing, as in the following example from Strawson 1950, p. 332:

(1) The table is covered with books.

There has been much discussion of such examples, and in particular of whether they are consistent with the kind of uniqueness-based semantics just mentioned. Many authors, as will be shown shortly, have maintained that such examples contain more descriptive content than meets the eye and that they are, after all, consistent with a uniquenessbased semantics when this hidden, or implicit, content is taken into account.

It has been proposed by several authors, for example, that incomplete definite descriptions (and quantifier domain restriction more broadly) crucially involve syntactic situation variables (Kuroda 1982, Recanati 1996, 2004, Kratzer 2004, Elbourne 2013). The basic picture urged by these authors is that definite descriptions contain phonologically null situation variables that can refer to particular situations. So the table, for example, does not end up attempting to pick out a putative only table in the world, but rather refers to the only table in $s^{*}$, where $s^{*}$ is a contextually salient situation. For example, in Elbourne 2013, I assume that definite descriptions have a syntax like that in (2), nouns have lexical entries like the one in (3), and that the definite article has the lexical entry in (4). ${ }^{2}$

(2) $\left[[\right.$ the table $\left.] \mathrm{s}_{1}\right]$

(3) $\llbracket$ table $\rrbracket=\lambda x . \lambda s . x$ is a table in $s$

(4) $\llbracket$ the $\rrbracket=\lambda f_{\langle\mathrm{e}, \mathrm{st}\rangle} \cdot \lambda s: s \in D_{\mathrm{s}} \& \exists ! x f(x)(s)=1 . \operatorname{lx} f(x)(s)=1$

Assuming that the index 1 in (2) is mapped to a situation $s^{*}$ consisting of the room the speakers are standing in at the moment of speech, (2) turns out to refer to the unique table in that room, if one exists.

But situations have not been the only, or even the most popular, elements to be drawn on in this connection. Many theorists have claimed that elements of other semantic types are involved and, indeed, that situation variables are not involved. So

\footnotetext{
${ }^{1}$ See Elbourne 2013 for my own views on definite descriptions. Briefly, I espouse a version of the Fregean analysis.

${ }^{2}$ As in Heim and Kratzer 1998, a colon indicates that we are dealing with a partial function, with the material after the colon and before the next period indicating the conditions that have to obtain in order for the function to apply; this is how the presuppositional nature of the definite article is captured in Heim and Kratzer 1998, Elbourne 2013, and other works. Since I am following in the Fregean tradition of work on the definite article (Frege 1891, 1892), the iota operator here creates expressions of type e, as it did in Peano 1906, contrary to the practice of Whitehead and Russell (1925).
} 
von Fintel (1994, p. 30-1), for example, claims that determiners are sisters to a phonologically null constituent consisting of a relation variable and an individual variable. So (1) would have an LF something like (5).

(5) $\left[\left[\left[\right.\right.\right.$ the $\left.\left[\mathrm{f}_{1} \mathrm{v}_{2}\right]\right]$ table] [is covered with books]]

In this example, the index 1 would be mapped to a salient function like the meaning of in and the index 2 would be mapped to the room containing the speaker and hearer; the definite article would have a denotation that takes two properties as arguments and effectively intersects them, among other things; and so the speaker turns out to be saying that the table in the room in question is covered with books. Stanley and Szabó (2000) advance a similar theory, the only significant difference being that they put relation and individual variables on NPs, not determiners.

It is worth noting, also, that prominent variants of what we might call the pragmatic enrichment approach to implicit content allow the inclusion of individual variables in implicit content. By 'pragmatic enrichment approach' I mean any theory that maintains that elements of implicit content are added only in the semantic interpretations of syntactic trees, these semantic interpretations being construed as language of thought strings. This approach has been advocated in various forms by Sperber and Wilson (1986), Neale (1990, 2004), Recanati (1993), Bach (1994), Bezuidenhout (1997), Carston (2002) and Hall (2008). Importantly, these authors do not seek to impose any type restrictions on elements of implicit content and do not seek to impose any restrictions on where such elements can appear. Sperber and Wilson (1986, pp. 176, 184), for example, propose only a pragmatic principle for arriving at suitably enriched propositional representations. ${ }^{3,4}$

By way of background, I should remark that theories of incomplete definite descriptions (and, more broadly, quantifier domain restriction and other implicit content) can be classified in various ways. ${ }^{5}$ Two distinctions are particularly relevant for the current article. The first concerns the semantic type of the implicit elements: are the implicit elements just (constituents referring to) situations or do they include elements of other semantic types, such as individual and relation variables? The second is the question of the level of representation at which those elements appear. For example, one could maintain that a relation variable and an individual variable appear next to determiners in the syntax, as von Fintel (1994) does, or one could maintain that such constituents make no appearance in the syntax and that concepts of the same or analogous semantic types first appear, as it were, in the language of thought (assuming that it makes sense to talk about concepts in the language of thought having types). The same variations are possible with a theory that uses situations. In this article, I will be primarily interested in the question of semantic type: I will be arguing that the implicit content associated with incomplete definite descriptions is presented in the form of definite descriptions of situations; and this conclusion could in principle be cashed out either in a version

\footnotetext{
${ }^{3}$ One partial exception to this general trend is Neale's $(1990,2004)$ explicit theory, which says that a sentence can be understood as having a meaning that would be yielded up by a sentence arrived at by adding further words to it in the overt syntax. This will naturally entail some restrictions on the types of elements that can be understood at any given point, these type restrictions being imposed via syntactic restrictions. Neale's theory is thus more contrained than, for example, the theory of Sperber and Wilson (1986), on which it is partially based. See Elbourne 2008 and footnote 21 in the present article for further discussion.

${ }^{4}$ This characteristic of pragmatic enrichment theories has been targeted before in arguments to the effect that theories of this kind overgenerate (Stanley 2002, 2005, Elbourne 2008, 2013). Recanati (2010, p. 11) and I (Elbourne 2008) consider some ways in which pragmatic enrichment theorists might defend themselves on this score, but without arriving at any detailed refutation of all the existing criticisms in this area.

${ }^{5}$ See Elbourne ming for further discussion.
} 
that has the implicit content enter via the syntax or in a version according to which content of this kind first arises in the language of thought. That said, I do think that there are some good reasons to talk in terms of syntactic constituents giving rise to implicit content, and to implicit content that involves situations, in particular; and so I will generally talk in those terms. I review those reasons in the next section.

\section{Syntactic Situation Variables}

Kratzer (2014, Section 5), building on work by Cresswell (1990), has shown that 'natural languages have the full expressive power of object language quantification over situations'. The following is an example that supports this conclusion (Kratzer 2014, Section 5):

(6) If, whenever it snowed, it had snowed much more than it actually did, the town plough would have removed the snow for us.

As Kratzer says, a traditional and widely influential way of handling modality, used, for example in Montague 1973, had modal operators shift evaluation indices. So a simple rule for must, for example, might look like this:

(7) $\llbracket$ must $\alpha \rrbracket^{w}=1$ iff $\llbracket \alpha \rrbracket^{w^{\prime}}=1$ for all $w^{\prime}$ that are accessible from $w$.

One consequence of this kind of theory, of course, is that the original evaluation index $w$ cannot be used for the evaluation of any constituents within $\alpha$, which is, instead, evaluated with respect to the newly introduced index $w^{\prime}$. But examples like (6) cast doubt on this kind of treatment. Imagine, with Kratzer (2014, Section 5), that the speaker of (6) is talking about the town of Amherst, Mass., over the last twenty years. Then, roughly speaking, the utterance introduces a set of situations $s$, the actual snowfalls in Amherst over the last twenty years, and then invites us to contemplate a set of counterfactual situations $s^{\prime}$, one for each situation $s$, in each of which it snowed more than it did in the corresponding situation $s$. From the counterfactual situations $s^{\prime}$, then, we have to be able to 'go back' (as Kratzer says) to the originally introduced situations $s$, in order to make the appropriate comparison. If the original situations $s$ were no longer available, which would be the case if we were analysing quantification over truth-supporting circumstances in the manner of (7), we would not be able to do this. If, however, situations are represented in the syntax, then we can simply insert syntactic situation variables interpreted as $s$ at any point where they are allowed syntactically, arbitrarily far from their original introduction and, in principle, with any number of differently indexed situation variables intervening. As Cresswell (1990) and Kratzer (2014) show in detail, this is in fact how natural languages seem to behave. I will assume from now on, then, that natural languages contain situation variables in the syntax which are bound by various operators. ${ }^{6,7}$

I will sometimes refer to situation variables in the syntax as situation pronouns.

\footnotetext{
${ }^{6}$ This is not the only way to model this expressive power, however. Cresswell (1990, p. 45) analyses similar examples as being evaluated at a series of worlds, rather than at just one world. I have argued briefly that putting situation variables in the syntax has an advantage over Cresswell's theory, in that the former approach can also use situation variables to deal with incomplete definite descriptions (Elbourne 2013, p. 149), thus disposing of two troublesome birds with one theoretically parsimonious stone. This argument naturally relies on there being a solution to the problem with which I deal in the current article.

${ }^{7}$ I give a lengthier introduction to this important and rather neglected set of considerations in Chapter 7 of Elbourne 2013.
} 


\section{A Formal System}

For some parts of our reasoning, it will be useful to have some formal precision. I therefore set out here a version of the formal system from Elbourne 2013. The syntactic component, however, was not laid out in that previous work. ${ }^{8}$

\subsection{Syntax}

In this article, I will adopt Stabler's 'minimalist grammars' syntactic framework (Stabler 1997, 2011, 2013), which is a formalization of ideas laid out in Chomsky 1995. The particular version I will adopt is what Stabler calls a directional minimalist grammar (i.e. one that allows linear order to be read off from trees and taken into account in the formulation of Merge, Stabler 2011, p. 635). In $\S \S 4.1 .1-4.1 .4$, I lay out the syntactic features, rules and lexical entries assumed in fairly austere form, largely for reference; in $\S 4.3$, I go through an example in a detailed and hopefully user-friendly manner.

\subsubsection{Features}

We distinguish between three kinds of features: semantic, phonological, and syntactic. Following the minimalist grammars literature, I will sometimes write the semantic features of a word by enclosing the conventional orthography in parentheses: (donkey), then, is the semantic value of the word donkey. The phonological features will be indicated by enclosing the orthography in phonemic slashes: /donkey/. When concentrating on the syntactic features of a word, I will often summarize the semantic and phonological features by writing down the conventional orthography unadorned: donkey. And a double colon will separate the syntactic features from the semantic and phonological ones. So the following, for example, is the lexical entry for the word donkey, indicating that it has a categorial feature $\mathrm{N}$ :

(8) donkey :: $\mathrm{N}$

A word can have more than one syntactic feature, of course, in which case the syntactic features are listed after the double colon without commas; the order in which they come is significant.

We distinguish between six kinds of syntactic features:

1. Categorial features. These include the familiar N, V, A, P, C, T, D. They also include $\mathrm{S}$, which is the type of situation pronouns in this system.

2. Selector features. A feature of the form $=\mathrm{X}$ on a syntactic head indicates that that head wants to take as an argument something of category X on its right. Similar combination with something to the left of the selecting head is shown by $\mathrm{X}=$.

3. Adjunction features (Frey and Gärtner 2002). A feature of the form $\approx X$ on the head of a constituent means that that constituent wants to left-adjoin to a constituent whose head is of category $\mathrm{X}$; i.e. the first constituent takes the second one on its right. Right-adjunction is shown by $\mathrm{X} \approx$.

4. Goal (or licensee) features. Features like -WH need to be licensed by something else, namely probe features.

\footnotetext{
${ }^{8}$ I am grateful to an anonymous NALS reviewer for urging me to take advantage of this opportunity for correcting that deficiency.
} 
5. Probe (or licensor) features. Features prefixed by a '+' sign are able to license goal features. They are triggers of movement. They include the following two varieties (Stabler 1997, Michaelis 2001):

(a) Strong features are written with capital letters: +WH. They produce overt movement.

(b) Weak features are written with lower-case letters: +wh. They produce covert movement.

And they also include the following, introduced here:

(c) Reconstruction features are written with italic capitals: $+W H$. They produce movement of phonological features only; syntactic and semantic features are left in the base position.

6. Features interpreted by syncategorematic rules, such as those that characterize lambda operators, traces, and situation pronouns.

\subsubsection{Trees}

1. When two constituents combine, one of them will always immediately project over the other. This is a primitive relation. The symbol $<$ represents this relation between sisters. So when a determiner combines with a noun and projects over it (as determined by the relevant lexical entries and rules) to form a DP, we write $\mathrm{D}<\mathrm{N}$. The more general relation of projection, simpliciter, is the reflexive and transitive closure of the relation of immediate projection (Stabler 1997). Reflexivity entails that nodes project over themselves and transitivity entails that a node projects over a node a node it projects over projects over.

2. A head is defined as follows (Stabler 1997). A node $x$ is a head of a node $y$ iff either

(a) $y$ is a leaf and $x=y$, or

(b) there is a node $z$ with the following properties:

i. $y$ is the parent of $z$;

ii. $z$ projects over any daughters of $y$; and

iii. $x$ is a head of $z$.

This definition has the following consequences: every head is a leaf; every leaf is head of itself; a node headed by $x$ dominates $x$; and every node has a unique head.

3 . The maximal projection of a head $x$ is a particular member of the set of nodes whose head is $x$, namely the one that no member of this set dominates.

\subsubsection{Rules}

The following abbreviations will be used in the presentation of the rules. $\tau[\alpha]$ denotes a tree whose head has a sequence of syntactic features whose first element is $\alpha$. Given a structure $\tau[\alpha], \tau$ denotes the result of erasing feature $\alpha$ and, if the head of $\tau[\alpha]$ has a double colon, changing the double colon to a single colon. ${ }^{9}$ Given a tree $\tau_{1}$ with subtree $\tau_{2}, \tau_{1}\left\{\tau_{2} \mapsto \tau_{3}\right\}$ is the result of replacing $\tau_{2}$ with $\tau_{3}$ in $\tau_{1}$. Given any tree or subtree $\tau, \tau^{M}$ is the maximal projection of the head of $\tau{ }^{10} \varepsilon$ indicates an empty sequence. And given a tree $\tau[\alpha],\lceil\tau\rceil$ indicates the syntactic features of $\tau$ with $\alpha$ erased

\footnotetext{
${ }^{9}$ The distinction between double colons in lexical items and single colons in syntactically complex structures will not be important in the present paper, but I maintain it for consistency with Stabler's work.

${ }^{10}$ Since the maximal projection of a node is another node, in this system, we should perhaps refer at this point to the tree dominated by the relevant maximal projection.
} 
correspondingly, $\left\lceil\tau^{M}\right\rceil$ indicates the syntactic features of the maximal projection of $\tau$ with $\alpha$ erased.

1. Merge. Since we are operating with a directional minimalist grammar, there are two cases:

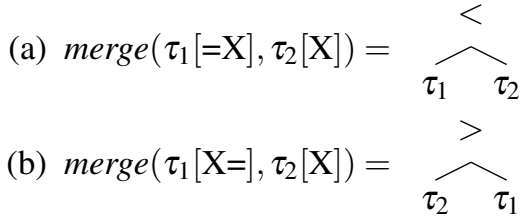

The $<$ and $>$ indicate the projection relation: $\tau_{1}$ projects over $\tau_{2}$ in both cases. This notation has the consequence that we can find the head of any node simply by following the arrows downwards until we reach a leaf.

2. Adjunction (Frey and Gärtner 2002)

(a) $\operatorname{adjoin}\left(\tau_{1}[\approx \mathrm{X}], \tau_{2}[\mathrm{X}]\right)=\overbrace{\tau_{1}}^{>} \overbrace{\tau_{2}[\mathrm{X}]}^{<}$
(b) $\operatorname{adjoin}\left(\tau_{1}[\mathrm{X} \approx], \tau_{2}[\mathrm{X}]\right)=\overbrace{\tau_{2}[\mathrm{X}]}^{<\tau_{1}}$

Note how in the case of adjunction, in contrast to that of (argument) Merge, the feature $\mathrm{X}$ is not erased from $\tau_{2}$ and the head of $\tau_{2}$ is the head of the whole structure.

3. Move (Stabler 1997, Michaelis 2001) takes place when a $+\mathrm{X}$ (strong), $+\mathrm{x}$ (weak) or $+X$ (reconstruction) probe feature occupies the head of a tree and attracts to it a corresponding - $\mathrm{X}$ goal feature with its accompanying maximal projection. Stabler (2011) maintains that movement only takes place when exactly one head in the tree has a corresponding goal feature; alternatively, one might formulate some version of the 'attract closest' condition (Chomsky 1995, p. 296). In this article, I will assume Stabler's stronger condition. Except in the case of reconstruction features, Move will operate slightly differently in the current system according as the head of the moving DP is of quantifier type or not. (In this system, the type of quantifiers is $\langle\mathrm{s},\langle$ est, $\langle$ esst,st $\rangle\rangle\rangle\rangle$.) Since there is also a difference between strong and weak features, there are five possibilities overall. ${ }^{11}$

(a) When the $-\mathrm{X}$ lexical item is of quantifier type, move applies to a tree $\tau_{1}[+\mathrm{X}]$ containing a subtree $\tau_{2}[-\mathrm{X}]$ as follows:

$$
\operatorname{move}\left(\tau_{1}[+\mathrm{X}]\right)=
$$

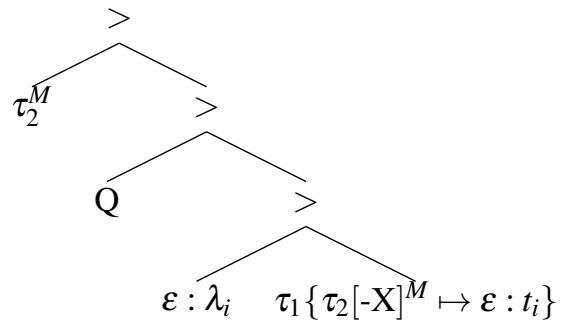

\footnotetext{
${ }^{11}$ So far I have stayed very close to the existing literature on the minimalist grammars framework. My treatment of movement, and in particular the introduction of a rule for total reconstruction, the insertion of the $\mathrm{Q}$ and lambda morphemes, the binding of traces, and the distinction between quantifier and other types, represents the first significant departure from what has already been laid down; but I think it is natural departure. The lambda morpheme in the syntax comes from Heim 1993 and is popularized in Heim and Kratzer 1998.
} 
Recall that $\varepsilon$ indicates an empty sequence. In the tree above, it indicates that the lambda-operator and the trace have no semantic or phonological features of their own; they have only syntactic features and will be interpreted by syncategorematic rules. The morpheme $Q$ makes certain things easier to pick out in the extended situations that characterize the nuclear scope of quantification; but it is not, I suspect, ultimately necessary. ${ }^{12}$ It has semantic features but no phonological or syntactic features. Writing just ' $Q$ ' is short for ' $Q$ : $\varepsilon$ '; that is, empty sequences of syntactic features are frequently not shown.

(b) When the $-\mathrm{X}$ lexical item is not of quantifier type, move applies to a tree $\tau_{1}[+\mathrm{X}]$ containing a subtree $\tau_{2}[-\mathrm{X}]$ as follows:

$\operatorname{move}\left(\tau_{1}[+\mathrm{X}]\right)=$

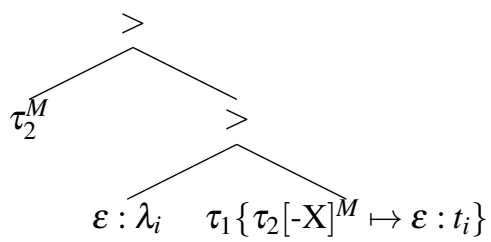

(c) When the $-\mathrm{X}$ item is of quantifier type, move applies to a tree $\tau_{1}[+\mathrm{X}]$ containing a subtree $\tau_{2}[-X]$ as follows:

$\operatorname{move}\left(\tau_{1}[+\mathrm{x}]\right)=$

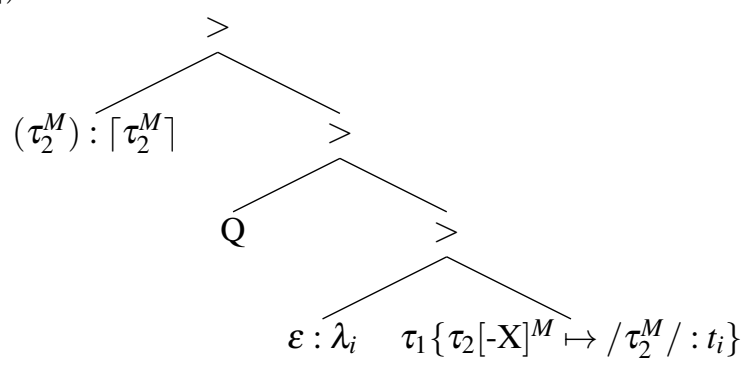

This is covert movement, since we are dealing with a weak $(+x)$ probe feature. The semantic and syntactic features of the relevant maximal projection raise (with the exception of the - $\mathrm{X}$ feature, which is erased), leaving behind the phonological features and a trace.

(d) When the $-\mathrm{X}$ item is not of quantifier type, move applies to a tree $\tau_{1}[+\mathrm{x}]$ containing a subtree $\tau_{2}[-\mathrm{X}]$ as follows:

$\operatorname{move}\left(\tau_{1}[+\mathrm{x}]\right)=$

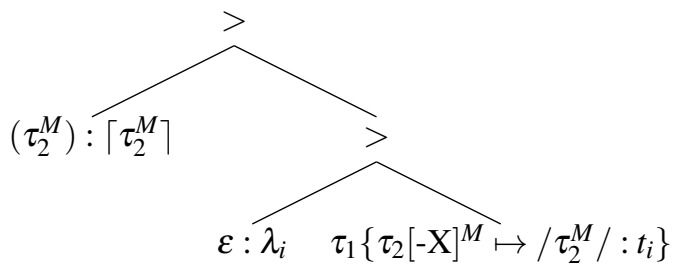

(e) Move applies to a tree $\tau_{1}[+X]$ containing a subtree $\tau_{2}[-\mathrm{X}]$ as follows:

$$
\operatorname{move}\left(\tau_{1}[+X]\right)=
$$

\footnotetext{
${ }^{12}$ The $Q$ morpheme is based on Büring's $(2004$, p. 38) $\leq$, which is in turn based on the prefixed, subscripted situation variables used in Heim 1990, p. 156. There is also a morpheme $Q A$, an analogous morpheme used with quantificational adverbs; it will be seen in Section 5.
} 


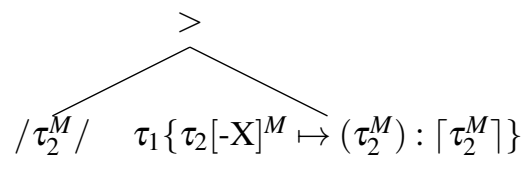

This is movement with total reconstruction. The phonological features of the DP move, but the semantic and syntactic features remain in the base position, with the exception of the goal feature -X, which is erased. Reconstruction is not dicussed, as far as I know, in the existing minimalist grammars literature, but I think the present treatment is natural: move with reconstruction is a kind of inverse version of covert movement, as detailed in rules $3 \mathrm{c}$ and $3 \mathrm{~d}$ above. This kind of treatment of total reconstruction, in which only the relevant phonological features ever move, has been defended in Sauerland and Elbourne 2002.

\subsubsection{Lexical Entries}

In the following representative listing, optional syntactic features are given in angle brackets: $\langle\alpha\rangle$. The others are compulsory. Semantic features will be given in the next section.

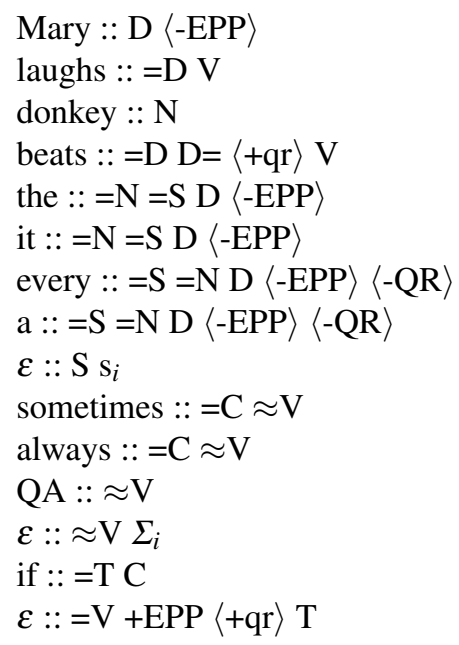

In addition to the above lexical items, we also meet with the following: $\mathrm{Q}$, which is inserted only by rule and contains only semantic features; traces, which are inserted only by rule and contain only syntactic features; and lambda operators, which are inserted only by rule and contain only syntactic features.

A word is in order about $\mathrm{T}$, as we normally write the last item in the above list. It would be unnecessary, and unfair on the reader, if I were to complicate the already complicated semantics of this article by adding in a serious treatment of tense. But, on the other hand, $\mathrm{T}$ as a syntactic head is important in contemporary syntactic theory and plays an important role in the current article in $\S 5$. As a compromise, therefore, between these conflicting demands, I have written down a lexical entry for $\mathrm{T}$ as we see above: it unrealistically contains no semantic features (and no phonological ones either, of course); but it does contain a fairly realistic complement of syntactic features. On the other hand, I see no useful purpose in further complicating things by including a little v or Voice head (Kratzer 1996), even though I believe there are good arguments for such a thing; and so my syntax is to that extent a simplification. 
I have chosen the feature-names 'EPP' and 'QR' for maximum clarity, without pretending that they offer up any deep understanding of what is going on. Indeed, the system as it stands suffers from a problem regarding the EPP: how do we ensure that that the right DP is raised to the canonical subject position (next to T)? In a structure with a subject and an object, for example, what is to prevent us putting a -EPP feature on the object and no such feature on the subject, with the result that the object will be raised over the subject and into the canonical subject position? (Note that, since transitive verbs have both $=\mathrm{D}$ and $\mathrm{D}=$ features they will initially form a VP shell, with subject and object immediately surrounding the verb; T is added in on top of this.) Stabler (1997) solves this problem by giving each lexical item with a categorial D feature a compulsory -CASE feature and giving both $\mathrm{T}$ and transitive verbs probe features that can attract -CASE features: a weak +case feature on transitive verbs triggers covert object shift ${ }^{13}$ and erasure of both the verb's +case feature and the object's -CASE feature; this leaves only one -CASE feature in the tree, on the subject, when T gets round to attracting such a feature. Some system like this might ultimately be necessary; but adding case features and compulsory covert object shift to the present fragment seemed to me to be an unnecessary complication. For present purposes, then, I will just stipulate that every TP has to have exactly one -EPP feature in it, placed on the external argument of the verb.

\subsection{Semantics}

\subsubsection{Ontological Ingredients (Kripke 1980, Kratzer 1989)}

1. $D_{\mathrm{s}}$, a set, the set of possible situations (including the set of thick particulars)

2. $D_{\mathrm{e}}$, a set, the set of possible thin particulars

3. $\leq$, a partial ordering on $D_{\mathrm{s}} \cup D_{\mathrm{e}}$ (intuitively, the part-of relation) such that at least the following conditions are satisfied:

(i) for no $s \in D_{\mathrm{s}}$ is there an $x \in D_{\mathrm{e}}$ such that $s \leq x$;

(ii) for all $s \in D_{\mathrm{s}}$ there is a unique $s^{\prime} \in D_{\mathrm{s}}$ such that $s \leq s^{\prime}$ and for all $s^{\prime \prime}$ : if $s^{\prime} \leq s^{\prime \prime}$, then $s^{\prime \prime}=s^{\prime}$.

4. $\wp\left(D_{\mathrm{s}}\right)$, the power set of $D_{\mathrm{s}}$, the set of propositions

5. $W$, a subset of $D_{\mathrm{s}}$, the set of maximal elements with respect to $\leq$, the set of possible worlds. For all $s \in D_{\mathrm{s}}$, let $w_{s}$ be the maximal element $s$ is related to by $\leq$ (as in (3ii) above).

These are the ontological ingredients of Kratzer 1989 modified so as to allow, with Kripke (1980, 44-6, 76-7) that individuals can appear in more than one possible world. I find this latter assumption easier to incorporate into a compositional semantics than the counterpart theory of Lewis (1968), which was adopted by Kratzer (1989).

\subsubsection{Rules (after Heim and Kratzer 1998 and Büring 2004)}

\section{Functional Application}

If $\alpha$ is a branching node and $\{\beta, \gamma\}$ the set of its daughters, then, for any assignment $g, \alpha$ is in the domain of $\llbracket \rrbracket^{g}$ if both $\beta$ and $\gamma$ are, and $\llbracket \beta \rrbracket^{g}$ is a function whose domain contains $\llbracket \gamma \rrbracket^{g}$. In that case, $\llbracket \alpha \rrbracket^{g}=\llbracket \beta \rrbracket^{g}\left(\llbracket \gamma \rrbracket^{g}\right)$.

\footnotetext{
${ }^{13}$ Object shift, of course, is overt in some languages and would hence involve a strong +CASE feature on transitive verbs.
} 


\section{Predicate Modification I (PMI)}

If $\alpha$ is a branching node and $\{\beta, \gamma\}$ the set of its daughters, then, for any assignment $g, \alpha$ is in the domain of $\llbracket \rrbracket^{g}$ if both $\beta$ and $\gamma$ are, and $\llbracket \beta \rrbracket^{g}$ and $\llbracket \gamma \rrbracket^{g}$ are of type $\langle\mathrm{e},\langle\mathrm{s}, \mathrm{t}\rangle\rangle$. In that case, $\llbracket \alpha \rrbracket^{g}=\lambda x . \lambda s . \llbracket \beta \rrbracket^{g}(x)(s)=1 \& \llbracket \gamma \rrbracket^{g}(x)(s)=1$.

3. Predicate Modification II (PMII)

If $\alpha$ is a branching node and $\{\beta, \gamma\}$ the set of its daughters, then, for any assignment $g, \alpha$ is in the domain of $\llbracket \rrbracket^{g}$ if both $\beta$ and $\gamma$ are, and $\llbracket \beta \rrbracket^{g}$ and $\llbracket \gamma \rrbracket^{g}$ are of type $\langle\mathrm{s}, \mathrm{t}\rangle$. In that case, $\llbracket \alpha \rrbracket^{g}=\lambda s . \llbracket \beta \rrbracket^{g}(s)=1 \& \llbracket \gamma \rrbracket^{g}(s)=1$.

4. Predicate Abstraction

For all indices $i$ and assignments $g, \llbracket \varepsilon: \lambda_{i} \alpha \rrbracket^{g}=\lambda x$. $\llbracket \alpha \rrbracket^{g^{x / i}}$.

5. Situation Binding

For all indices $i$ and assignments $g, \llbracket \varepsilon: \Sigma_{i} \alpha \rrbracket^{g}=\lambda s . \lambda s^{\prime} \cdot \llbracket \alpha \rrbracket^{g^{s^{\prime}} / i}(s)\left(s^{\prime}\right)$.

6. Traces and Pronouns

If $\alpha$ is a trace or a pronoun, $g$ is a variable assignment, and $i \in \operatorname{dom}(g)$, then $\llbracket \alpha_{i} \rrbracket^{g}=g(i)$.

7. Lexical Terminals (LT)

If $\alpha$ is a terminal node occupied by a lexical item, then $\llbracket \alpha \rrbracket$ is given by the semantic features of $\alpha(\llbracket \alpha \rrbracket=(\alpha))$.

Variable assignments in this system are functions from the natural numbers to individuals or situations; the 'pronouns' of the Traces and Pronouns rule will be situation pronouns. $g^{x / i}$ is the variable assignment that is just like $g$ except that $i$ is mapped to $x$.

In addition to the above rules that operate on the object language, we also need the following rules to operate on the metalanguage when doing derivations.

- $\lambda$-Conversion I

$\left[\lambda u_{\tau} . M\right]\left(N_{\tau}\right)=[N / u] M$

- $\lambda$-Conversion II

$$
\begin{aligned}
& \lambda u_{\tau}: f(u)=1 .\left[\ldots\left[\lambda v_{\tau}: g(v)=1 . M\right](u) \ldots\right] \\
= & \lambda u_{\tau}: f(u)=1 \& g(u)=1 .[\ldots[u / v] M \ldots]
\end{aligned}
$$

The first rule is a summary of normal $\lambda$-conversion. The notation $[N / u] M$ means ' $M$ so altered as to replace free occurrences of $u$ with $N$ (and with bound variables altered, if necessary, so as to avoid clashes)' (Hindley and Seldin 2008, p. 8). The second rule is designed to deal with domain conditions and bound variables. We should first note that domain conditions are officially conceived, in this system, as functions. For example, the lexical entry for the definite article, which we informally write as (9), is more properly written as in (10):

(9) $\llbracket$ the $\rrbracket=\lambda f_{\langle\mathrm{e}, \mathrm{st}\rangle} \cdot \lambda s: s \in D_{\mathrm{s}} \& \exists ! x f(x)(s)=1 . \operatorname{lx} f(x)(s)=1$

(10) $\llbracket$ the $\rrbracket=\lambda f: E S T(f)=1 . \lambda s: S(s)=1 \& E X(\langle f, s\rangle)=1.1 x f(x)(s)=1$

Here, EST is a function that maps entities to 1 if and only if they are of type $\langle\mathrm{e}, \mathrm{st}\rangle$; $S$ is a function that maps entities to 1 if and only if they are of type $s$; and $E X$ is a function that maps a pair of entities $\langle f, s\rangle$ to 1 if and only if there is exactly one individual $x$ such that $f(x)(s)=1$. The second rule now says that, when a function with a domain condition $\left(\left[\lambda v_{\tau}: g(v)=1 . M\right]\right)$ takes a bound variable $(u)$ as argument, the lambda conversion goes ahead in the normal way, with the additional stipulation that the domain condition that applied $(g(v)=1)$ now becomes added to the domain condition that applies to the lambda $\left(\lambda u_{\tau}\right)$ that binds the bound variable in question. The idea is that, when a function with a domain condition meets a bound variable, as 
opposed to an object, it is impossible to tell there and then, as it were, whether the condition is met. To do so would require looking ahead to see what, if anything, the larger function was to be applied to. So in order to ensure that it is not lost, the condition is passed up to the level at which the bound variable is introduced. There is an example of this rule in action in Elbourne 2013, pp. 49-51.

\subsubsection{Semantic features of lexical items}

I write down these semantic features in a traditional way; but according to the broadly Chomskyan, internalist perspective on language that I adopt, they are ultimately to be envisaged as internal mental entities. I would maintain that in using the traditional mathematical formalism we are taking advantage of what Wigner (1960) called 'the unreasonable effectiveness of mathematics in the natural sciences': theories in physics, biology, and so on, use mathematics successfully in order to illuminate aspects of the structure of the natural world, even though it is not clear why mathematics should be so apt for this purpose. If biologists can do it, the same technique can surely be applied legitimately by semanticists who are sympathetic to the internalist picture of meaning. Naturally, there are issues here; but exploring them is not the purpose of this article.

For any lexical item $\alpha, \llbracket \alpha \rrbracket=(\alpha)$, in the terminology adopted earlier.

The following is a representative list of lexical items:

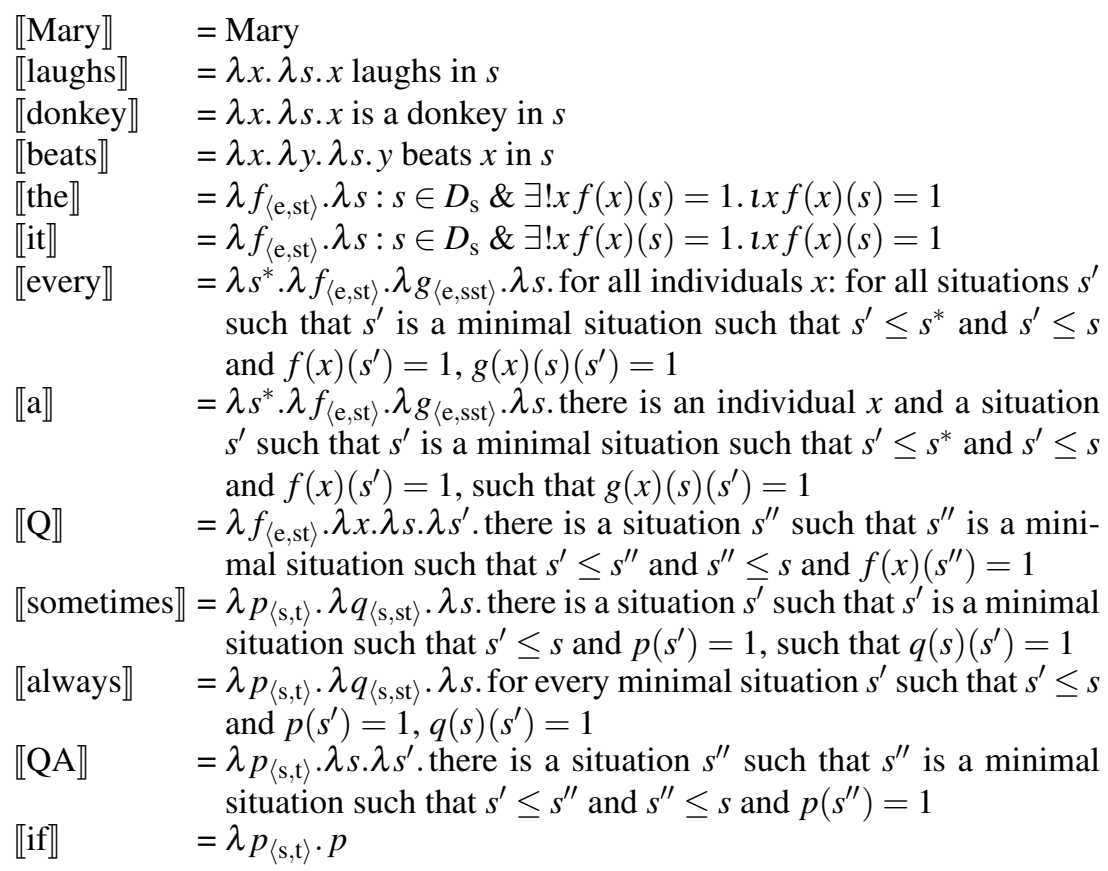

As will be seen from the above lexical entries, every and $a$ and all other quantifiers take a situation pronoun as their first argument. ${ }^{14}$ These situation pronouns have the function of bringing about quantifier domain restriction. A QP [[every $\mathrm{s}_{1}$ ] donkey],

\footnotetext{
${ }^{14}$ I am here following Büring (2004, p. 40). A similar idea is used to great effect by Keshet (2008) and Schwarz (2012), but these authors put situation pronouns only on strong determiners. I will not attempt here to arbitrate between the merits of these two ways of doing this.
} 
for example, will quantify not over all donkeys simpliciter, but over all donkeys in a particular situation $s^{*}$, given that the index 1 is mapped to $s^{*}$.

\subsection{An Example}

In this section, in order to illustrate the above system, I will go through the syntax and semantics of one example in some detail. The example sentence is (11):

(11) Mary saw every donkey.

Since it involves quantification, this sentence involves several features that will crop up later in the analysis of the crucial data of this article.

This example will make use of the following vocabulary:

(12) every :: =S =N D -QR

$$
\begin{aligned}
& \varepsilon:: \mathrm{S} \mathrm{s}_{1} \\
& \text { donkey }:: \mathrm{N} \\
& \text { saw }::=\mathrm{D} \mathrm{D}=\mathrm{V} \\
& \text { Mary }:: \mathrm{D}-\mathrm{EPP} \\
& \varepsilon::=\mathrm{V}+\mathrm{EPP}+\text { qr } \mathrm{T}
\end{aligned}
$$

We first take every and the situation pronoun and combine them by Merge:

$$
\text { every }:=\overbrace{\mathrm{N} D-\mathrm{QR}}^{<: \mathrm{s}_{1}}
$$

Note how the $=\mathrm{S}$ feature on the head and the categorial $\mathrm{S}$ feature on the argument are erased as part of the process. We then Merge donkey, and the analogous process takes place:

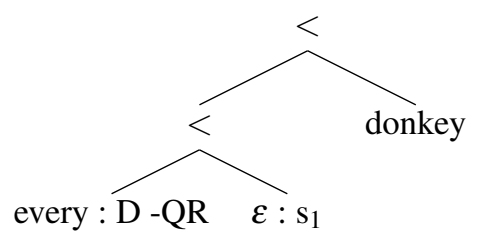

The word saw wants to take a constituent whose head has a categorial feature D. Follow the arrows down from the top node in (14) and you will see that (14) is just such a constituent. So we combine saw and (14) by Merge:

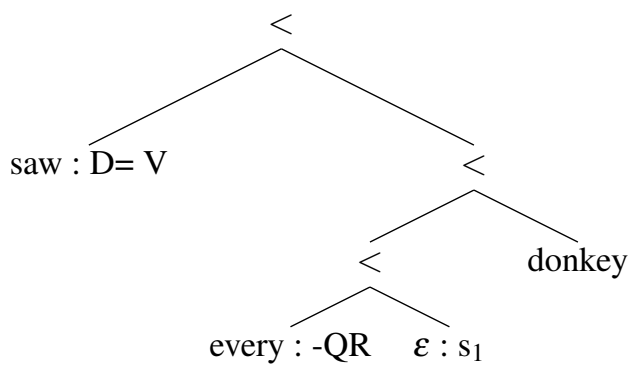

The head of this structure, saw, subcategorizes on its left for a constituent whose head has a D feature. Mary fits the bill, so we can combine Mary and (15) by Merge: 
(16)

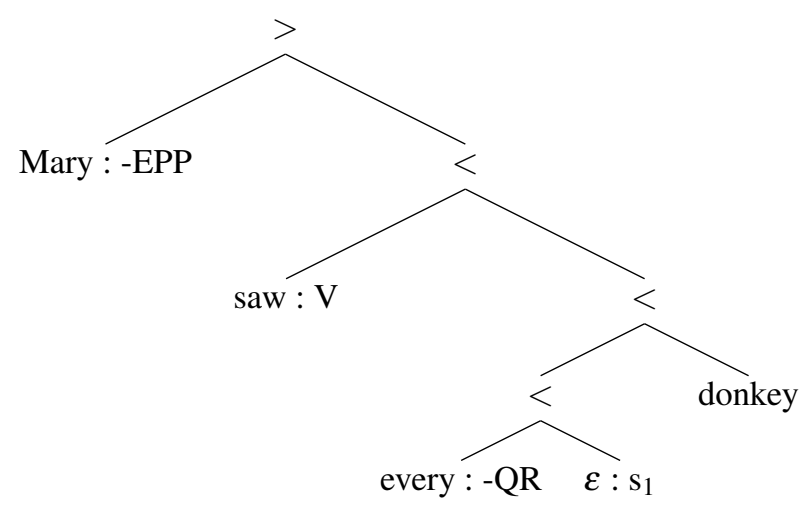

The head of this structure is saw, which has a $\mathrm{V}$ feature. This means that the structure is the kind of thing that $\mathrm{T}$ likes to combine with. We combine them by Merge:

(17)

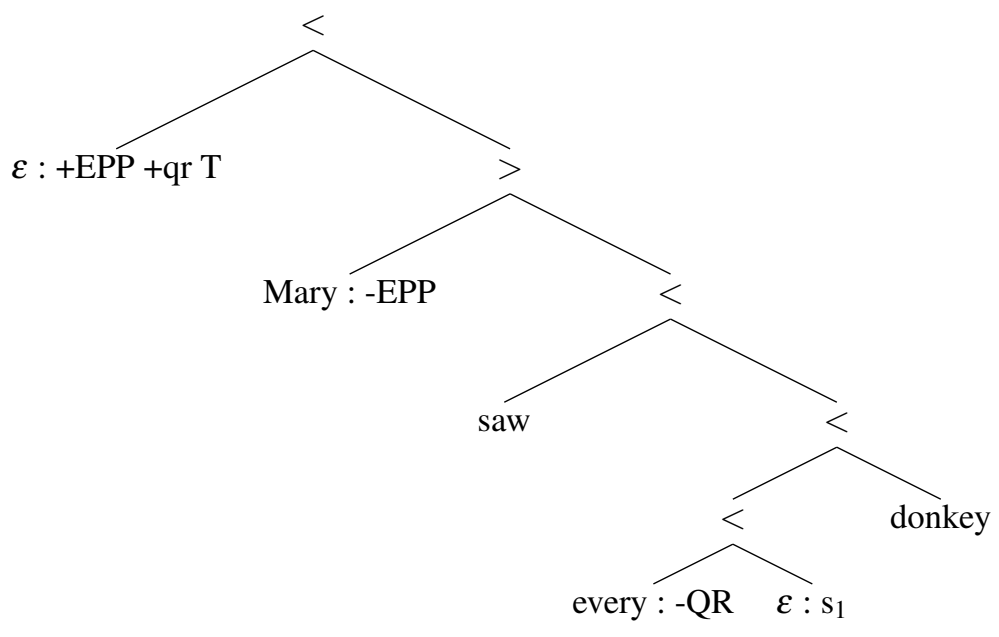

The strong +EPP feature on $\mathrm{T}$ triggers movement (rule $3 \mathrm{~b}$ above): 
(18)

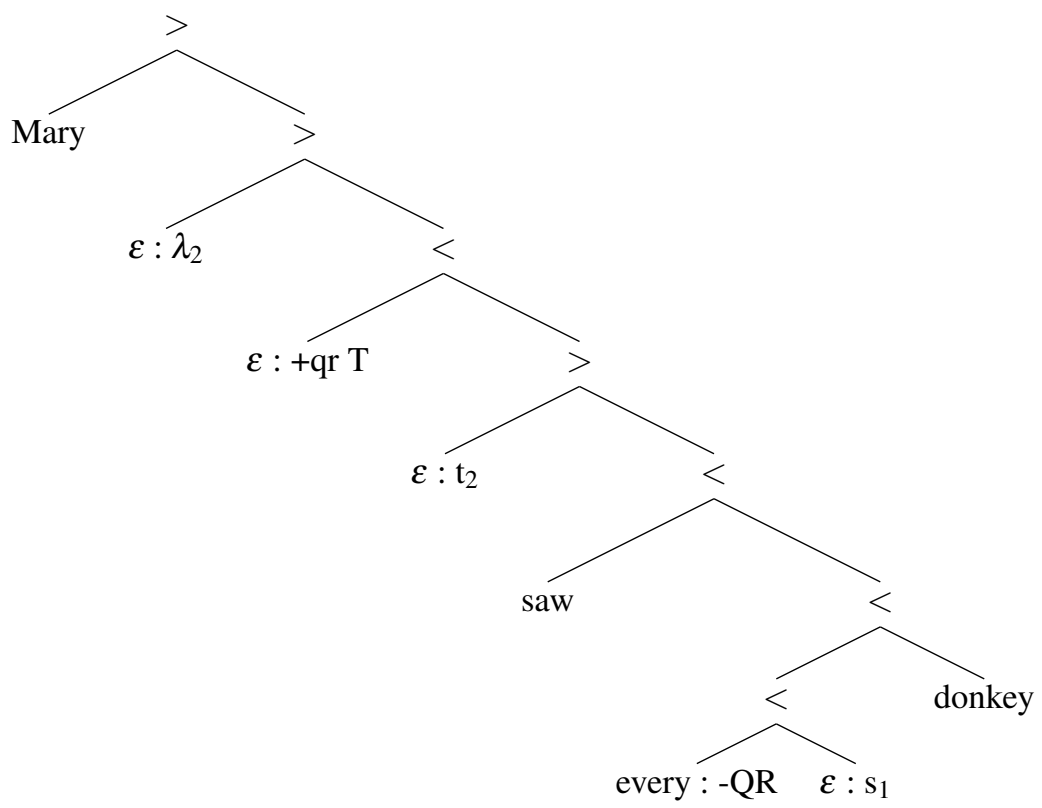

This structure is still headed by $\mathrm{T}$, the first feature in whose feature-list is now +qr. This triggers covert movement via rule $3 \mathrm{c}$ above. Note how this rule, like all the movement rules, talks about structures with heads of a certain kind triggering movement. The heads can be embedded arbitrarily far and still trigger movement if they bear appropriate features. We arrive, then, at the following syntactic tree:

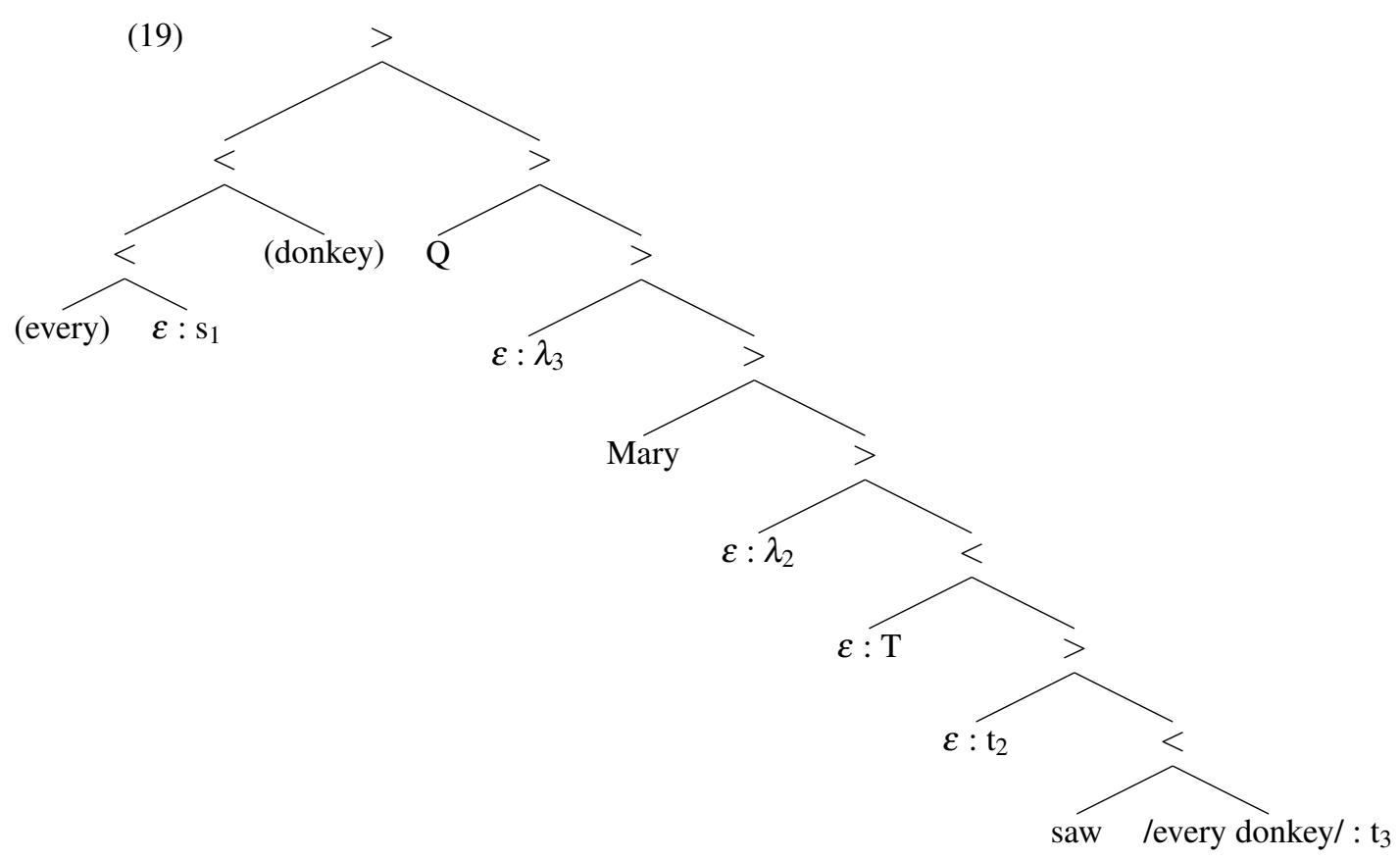

Note how this one structure encodes both the semantic features and the phonological features, all in the correct positions for interpretation at their respective interfaces. It 
thus does the work of both LF and PF representations in versions of syntax that separate these two.

Stabler (1997) maintains that a well formed tree for a whole sentence will have no syntactic features left in it besides the categorial feature that indicates the category of the whole tree ( $\mathrm{T}$ or $\mathrm{C}$ ). The current system differs, in that it allows syntactic features to remain in a tree of category $\mathrm{T}$ if they are interpreted by syncategorematic rules. This is the case with all the syntactic features in the above tree except T. But no other syntactic features should be left in a tree of category $\mathrm{T}$.

I can be briefer about the semantics of the above example. Assume that the free situation pronoun $s_{1}$ is mapped to a contextually salient situation $s^{*}$, perhaps a field through which Mary is walking at a certain time (and all its animate inhabitants). Then, assuming that semantically vacuous nodes like $\mathrm{T}$ are just ignored, a straightforward calculation using the above system gives the following as the truth conditions for (19):

(20) $\lambda s$. for all individuals $x$ : for all situations $s^{\prime}$ such that $s^{\prime}$ is a minimal situation such that $s^{\prime} \leq s^{*}$ and $s^{\prime} \leq s$ and $x$ is a donkey in $s^{\prime}$, there is a situation $s^{\prime \prime}$ such that $s^{\prime \prime}$ is a minimal situation such that $s^{\prime} \leq s^{\prime \prime}$ and $s^{\prime \prime} \leq s$ and Mary saw $x$ in $s^{\prime \prime}$

These truth conditions are intuitively adequate.

\section{Situations and Donkeys}

Using situation pronouns to account for covariation in donkey sentences is a well established technique (Heim 1990, Elbourne 2001, 2013, Büring 2004) and I do not propose to give an extensive introduction to it here. Here is a brief exemplification of this kind of analysis, based on the formal system given above. I will, however, give more attention to the syntax of the relevant examples than is sometimes accorded it.

Take a donkey sentence like (21). ${ }^{15}$

(21) If a man beats a donkey, the donkey always kicks the man.

It has been claimed by Berman (1987) and Heim (1990) that quantificational adverbs like always impose the structure in (22) on their LFs; and I have used this assumption myself in previous work (Elbourne 2005, 2013).

(22) [[always [if $\alpha]] \beta]$

It is seldom if ever explained, however, how this structure relates to the surface syntax of sentences like (21), and how it can be built up. So I will devote some time to explaining one way in which this might work before going on to the semantics.

In brief, I think that structures like (22) are basically VPs. The constituent $\beta$ (the donkey kicks the man, in the case of (21)) is a VP shell with a VP-internal subject. The constituent [always [if $\alpha$ ]] is an adverbial phrase that adjoins to the VP shell. Above this complex VP, in the current system, there will of course be a T node. In order to obtain the pronounced version, the VP-internal subject (the donkey in the current example) raises to $\mathrm{T}$ and then the if-clause is topicalized above that. We thus arrive

\footnotetext{
${ }^{15}$ It was recognized as early as Strawson 1961, p. 394, that definite descriptions could have covarying readings in donkey anaphoric configurations, although Strawson in this article does not actually call the constructions in question examples of donkey anaphora. The work of Geach (1962), which introduced the problem of donkey anaphora to modern audiences, was still a year away. Most donkey anaphora in the current article will involve overt definite descriptions.
} 
at (21). But for purposes of interpretation, both these movements are reconstructed and we are left with something that looks like (22). That, I propose, is the syntax in a nutshell.

Here are some more details. The syntactic system in $\S 4.1$ will give us a structure with following outlines:

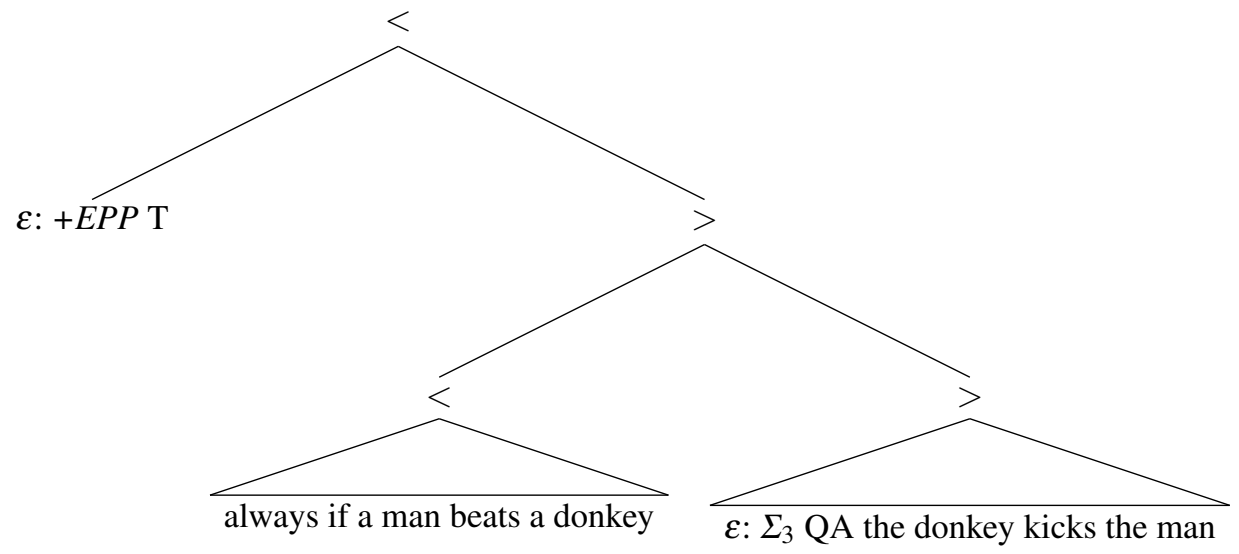

In more detail, the VP shell looks like this:

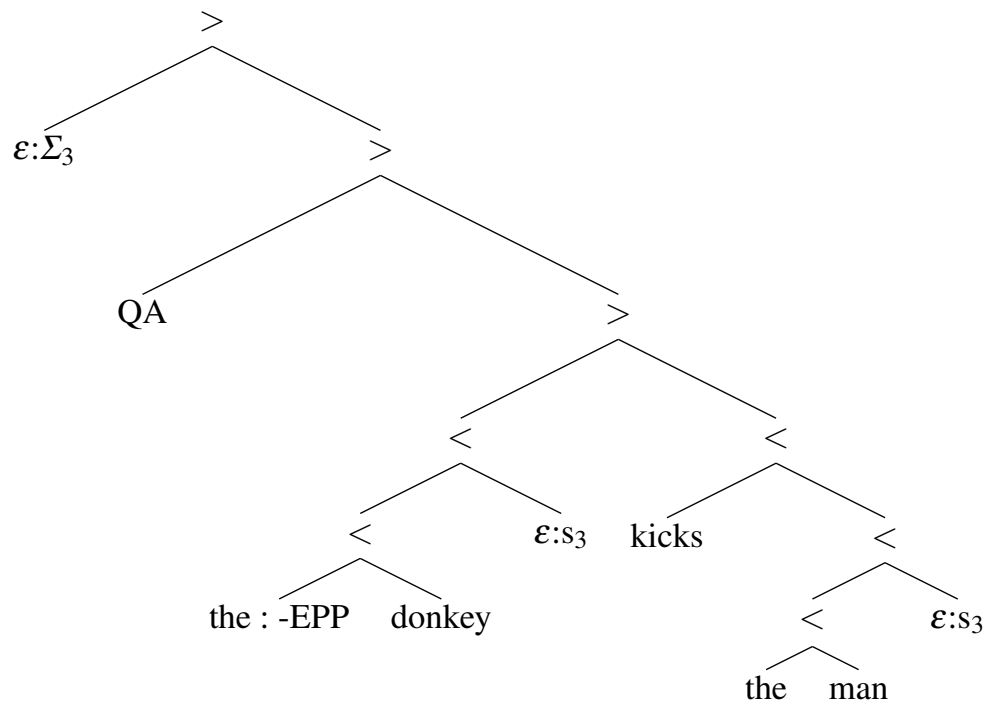

I say 'VP shell', in order to distinguish this constituent from the large adverbial phrase headed by always, but, as you can see, it is a bit larger than just a VP shell. The heads $\varepsilon: \Sigma_{3}$ and $\mathrm{QA}$, as we see in $\S 4.1 .4$, are adverbs, containing $\mathrm{a} \approx \mathrm{V}$ feature before they are merged. They are entirely optional, then, but are placed here on this occasion solely because of the reading we are interested in. In the present context, with the phrase headed by always being present, QA is necessary in order to turn the VP shell into something of the right semantic type: always demands a second argument of type $\langle\mathrm{s}, \mathrm{st}\rangle$, while VPs on their own are of type $\langle\mathrm{s}, \mathrm{t}\rangle .^{16}$ The morpheme $\varepsilon: \Sigma_{3}$ is also optional and could

\footnotetext{
${ }^{16}$ Basically QA is analogous to Q, helping to make certain entities in the situations defined by the restrictors of this kind of quantification easier to pick out in the extended situations defined by the nuclear scope. I suspect it is ultimately unnecessary, but it makes the truth conditions a bit less difficult to read.
} 
be omitted altogether if the reading we were interested in involved referential situation variables in the nuclear scope. But the reading in question requires bound situation variables and so $\varepsilon: \Sigma_{3}$, which is a situation binder, is required. ${ }^{17}$

The details of the adverbial phrase are shown in (25).

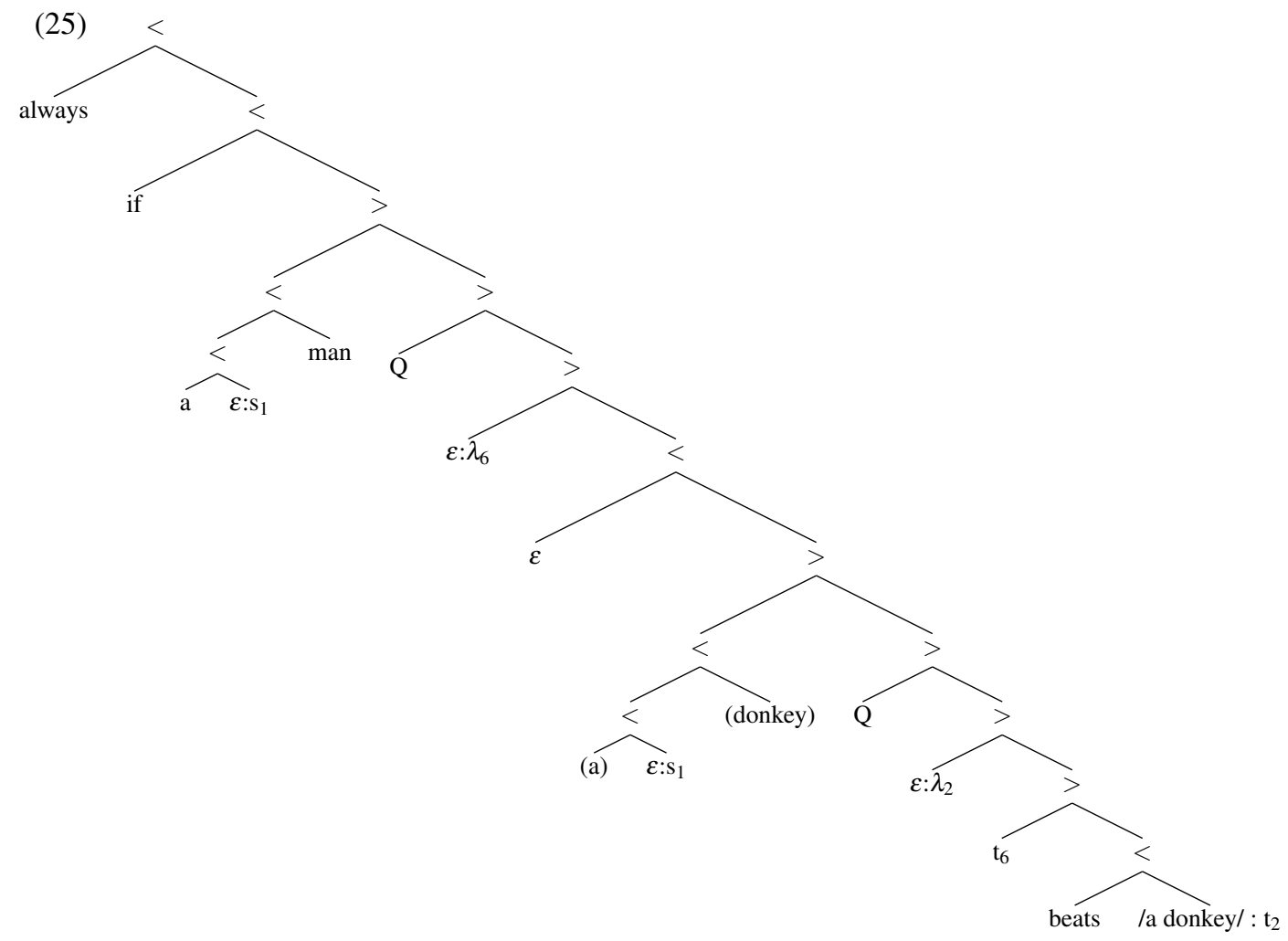

This is constructed entirely straightforwardly according to the syntactic system laid out in $\S 4.1$. The only points worthy of note are the empty sequence $\varepsilon$, which is all that is left of an original $\mathrm{T}$ head after the $\mathrm{T}$ feature has been erased upon combination with if ; and the fact that a $+\mathrm{qr}$ feature on beats has caused QR of the object.

As mentioned, the structure interpreted will be (23), whose content has now been shown in detail. This structure is built and then, as I said, the subject the donkey is raised due to the $+E P P$ feature on the higher T node and the if-clause is topicalized. I will not bother to lay out formal mechanisms for the latter procedure; but I foresee no difficulties in doing so. ${ }^{18}$ In order for (23) to be the input to interpretation, the subject

\footnotetext{
${ }^{17}$ It would not be possible to add QA and $\varepsilon: \Sigma_{3}$ in the opposite order to the one shown, making QA have scope over $\varepsilon: \Sigma_{3}$. For the interpretation rule given for $\varepsilon: \Sigma_{3}$ in $\S 4.2 .2$ puts two variables $s$ and $s^{\prime}$ as arguments to be taken by the sister of $\varepsilon: \Sigma_{3}$, that is, the VP in the hypothetical case we are considering. The denotation of the VP, given the VP-internal subject, will be a proposition, and will begin, as it were, with something like ' $\lambda s$.' only. It will not begin with something like ' $\lambda s . \lambda s^{\prime}$. ', which is what would be necessary to handle the arguments that the rule for $\varepsilon: \Sigma_{3}$ would give it. So we need QA to apply to the VP first, in order to make it be of the right type for $\varepsilon: \Sigma_{3}$. Overall, given the presence of always and the non-referential situation pronouns in the nuclear scope, we have to have [ $\varepsilon: \Sigma_{3}$ [QA VP]], by purely semantic principles. Since the semantics gives us this ordering, I have not attempted to enforce it by means of syntactic features.

${ }^{18}$ We would expect, if the basic picture given here is correct, that one would be able to raise the subject without topicalizing the if-clause. I think this is what we see in sentences like Mary always, if she goes for a walk, takes an umbrella. A version of this sentence with when in place of if, which might be found more natural, will work in exactly the same way.
} 
and the if-clause must reconstruct; this entails that the original movement took place by means of rule $3 \mathrm{e}$ above.

In (26) I present a compressed version of the structure abbreviated more radically by (23). I show all the interpreted morphemes but omit semantically vacuous material.

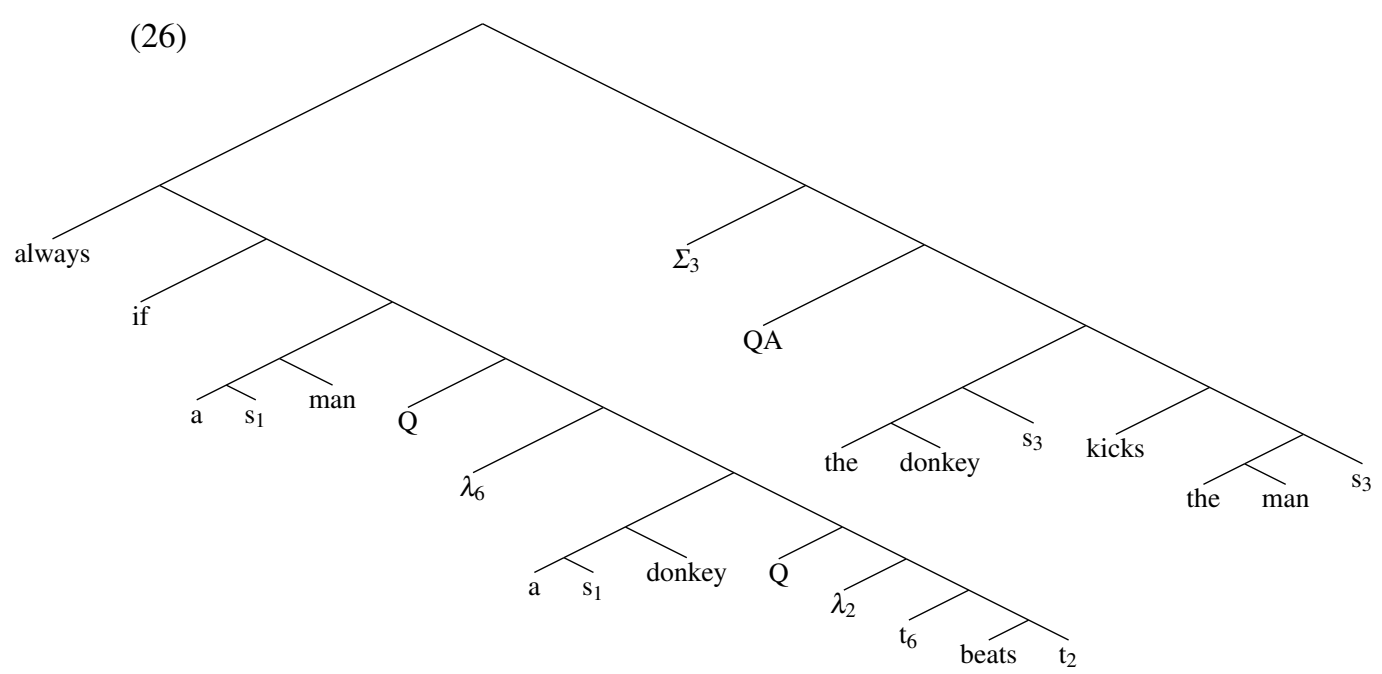

Since the details of the syntax will not be my central concern from now on, I will present subsequent syntactic trees in this spartan but functional form.

Applying our semantic system to (26), we obtain the truth-conditions in (27); the contribution of the antecedent of the conditional is indented in order to aid readability; the structure of the situations posited is shown in (28).

(27) $\lambda s$. for every minimal situation $s^{\prime}$ such that $s^{\prime} \leq s$ and

there is an individual $x$ and a situation $s^{\prime \prime \prime}$ such that $s^{\prime \prime \prime}$ is a minimal situation such that $s^{\prime \prime \prime} \leq s^{*}$ and $s^{\prime \prime \prime} \leq s^{\prime}$ and $x$ is a man in $s^{\prime \prime \prime}$, such that there is a situation $s^{\prime \prime \prime \prime}$ such that $s^{\prime \prime \prime \prime}$ is a minimal situation such that $s^{\prime \prime \prime} \leq s^{\prime \prime \prime \prime}$ and $s^{\prime \prime \prime \prime} \leq s^{\prime}$ and there is an individual $y$ and a situation $s^{\prime \prime \prime \prime \prime \prime}$ such that $s^{\prime \prime \prime \prime \prime \prime}$ is a minimal situation such that $s^{\prime \prime \prime \prime \prime} \leq s^{*}$ and $s^{\prime \prime \prime \prime \prime} \leq s^{\prime \prime \prime \prime}$ and $y$ is a donkey in $s^{\prime \prime \prime \prime \prime}$, such that there is a situation $s^{\prime \prime \prime \prime \prime \prime \prime}$ such that $s^{\prime \prime \prime \prime \prime \prime \prime}$ is a minimal situation such that $s^{\prime \prime \prime \prime \prime} \leq s^{\prime \prime \prime \prime \prime \prime \prime}$ and $s^{\prime \prime \prime \prime \prime \prime \prime} \leq s^{\prime \prime \prime \prime}$ and $x$ beats $y$ in $s^{\prime \prime \prime \prime \prime \prime \prime}$,

there is a situation $s^{\prime \prime}$ such that $s^{\prime \prime}$ is a minimal situation such that $s^{\prime} \leq s^{\prime \prime}$ and $s^{\prime \prime} \leq s$ and $\imath z z$ is a donkey in $s^{\prime}$ kicks in $s^{\prime \prime} \imath z z$ is a man in $s^{\prime}$ 
(28)

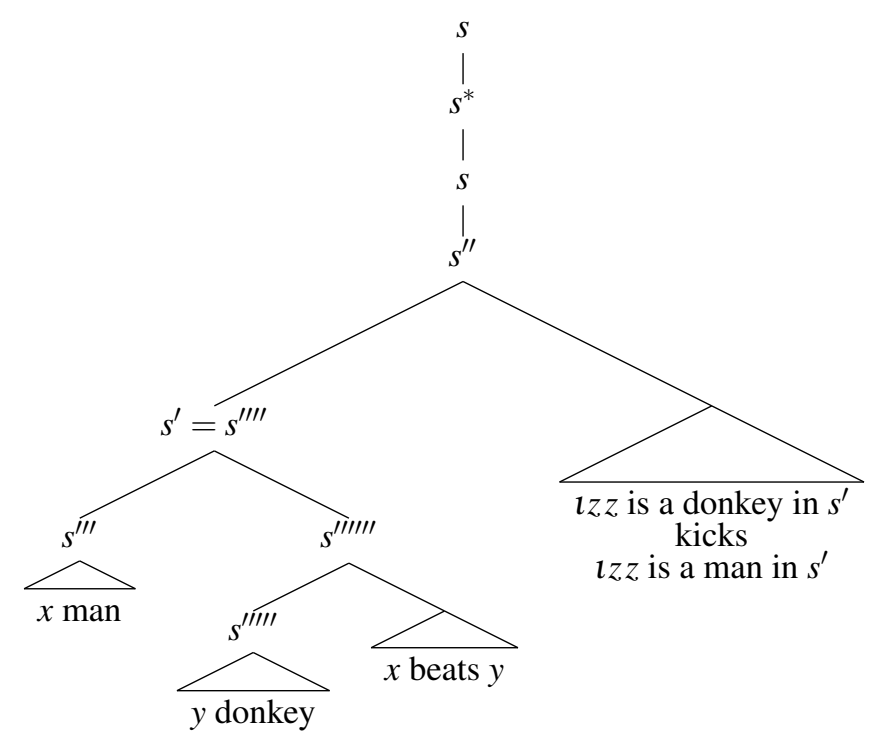

These truth conditions are intuitively accurate.

\section{Situation Variables Only?}

The argument relies on some new data, which are as follows. Small italics denote downstressing, which in turn indicates, roughly, that the phrase in question conveys old information - a property repeated from another part of the sentence in these cases. ${ }^{19}$

(29) a. In this village, if a farmer owns a donkey, he beats the donkey and the priest beats the donkey too.

(strict, *sloppy)

b. In this village, if a farmer owns a donkey, he beats the donkey he owns and the priest beats the donkey he owns too.

(strict, sloppy)

On one reading of (29b), the village priest is assumed to own and claimed to beat his own donkey; whereas no such claim can be made with (29a). The basic observation, in other words, is that, given a sentence with a donkey-anaphoric definite description containing no overt pronouns, a repetition of the definite description in a downstressed continuation does not give rise to a sloppy reading. ${ }^{20}$

These data present a significant problem for any theories that allow a relation variable and an individual variable to figure in implicit content in the ways we have just been examining. Suppose, for example, that we are dealing with a theory like that of von Fintel (1994). Then the two occurrences of the donkey in (29a) could look like this:

(30) $\left[\left[\right.\right.$ the $\left.\left[f_{1} v_{2}\right]\right]$ donkey]

\footnotetext{
${ }^{19}$ The literature on the information-theoretic effects of focus and downstressing is huge. For discussion of downstressed definite descriptions in particular, see Umbach 2001.

${ }^{20}$ The effect is replicable with donkey sentences built around quantifiers and relative clauses, and also with VP-ellipsis instead of downstressing; but we have perhaps a slightly better knowledge of what is present when we are dealing with downstressing. For the sake of time and space, I will not deal with examples of the Every farmer who owns a donkey... type in this article; interested readers are referred to Elbourne 2013, p. 180.
} 
The variable $\mathrm{f}_{1}$ could presumably pick up the salient function 'owned by' $(\lambda x . \lambda y . y$ is owned by $x$ ) and the individual variable $\mathrm{v}_{2}$ could be bound by (a lambda operator below) the subject. This kind of theory predicts, then, that the two occurrences of the donkey in (29a) should be able to mean 'the donkey owned by $x$ ', with $x$ bound by the subject each time. This kind of theory predicts, then, that (29a) should have a sloppy reading, like (29b) does, contrary to fact.

The problem posed by these data extends not just to Stanley and Szabó 2000, a syntactic approach rather similar to von Fintel's, but also to all of the pragmatic enrichment approaches that allow elements of the relevant types (functions, bound individual variables) to be added in conceptual representations; as I said above, that means all of them, as far as I know. ${ }^{21}$

If, on the other hand, we maintain that no individual variables are possible in the implicit content associated with incomplete definite descriptions, we will avoid predicting unwelcome sloppy readings in examples like these. This, of course, is exactly the approach taken by the theory being explored here, which maintains that this implicit content is supplied solely by situation pronouns. ${ }^{22,23}$

But how exactly would the current theory analyse (29a)? Let us first introduce a variant that is more transparent in a certain regard. There is no overt quantifier in (29a), even though there is evidently quantification over various instances. To abstract away from this irrelevant difficulty, here is a variant of the example with an explicit quantificational adverb:

(31) In this village, if a farmer owns a donkey, he always beats the donkey and the priest beats the donkey too.

(strict, *sloppy)

Following Berman (1987) and Heim (1990) once more, let us assume that quantificational adverbs impose the structure in (32) on their LFs. ${ }^{24}$

\footnotetext{
${ }^{21}$ For the case of Neale's $(1990,2004)$ theory, described in footnote 3, note that (29b) precisely constitutes a sentence constructed from (29a) by adding more words in the overt syntax. According to this theory, then, (29a) should have any meaning that (29b) has, including the relevant sloppy reading. But it does not.

${ }^{22}$ An anonymous reviewer points out that, according to the ontology adopted in the current article, individuals are situations: Kratzer (1989), following Armstrong (1978), maintains that individuals can be construed as thin particulars with all their non-relational properties. How, then, is it possible to enforce the strict separation between situations and individuals on which I am relying at this point? The answer is that there is still a conceptual distinction between situations and individuals: individuals are strictly the very particular kind of situation just described; situations in general can be both smaller and larger than individuals. Resting on this foundation, it is likewise possible to distinguish between situations and individuals for the purposes of semantic typing: some variables, for example, might range over individuals only and some might range over situations in general. Finally (and this is the most important factor in this context) it is possible to distinguish between operators that bind or quantify over individuals only and operators that bind or quantify over situations. The current argument, then, aims to show that a particular kind of binding of individual variables (in conjunction with relation variables) by subjects (or lambda operators just below them) cannot be going on here.

${ }^{23} \mathrm{An}$ anonymous reviewer points to the case of definite descriptions formed with relational nouns like author, pointing out that Schwarz (2009) has argued that such nouns come with a phonologically null individual variable referring to their relatum. If this is correct, then definite descriptions formed from such nouns will contain individual variables. This, however, is consistent with my position. My position is just that incomplete definite descriptions quite generally (that is, including ones that do not contain relational nouns) come with a means of providing implicit content and that this general-purpose implicit content does not consist of a relation variable plus an individual variable in the style of von Fintel (1994), Stanley and Szabó (2000) and others. Relational nouns are a separate and potentially complex topic that is not the focus of this article; I abstract away from them by generally using, in my examples, definite descriptions that do not contain them.

${ }^{24}$ I use the term $L F$ simply to indicate that the syntactic structures in question are the input to semantic interpretation. I do not mean to imply a distinction between LF and PF along the lines of Chomsky 1993 and
} 


\section{(32) [[always [if $\alpha]] \beta$ ]}

What LF structure we assign to (31) will depend on what we take the two conjuncts of and to be. Presumably the sentence the priest beats the donkey too forms one of the conjuncts. There seem to be two possibilities for the overall structure. Either the priest beats the donkey too is coordinated with he beats the donkey, thus forming a continuation of the consequent of the conditional; or it is coordinated with if a farmer owns a donkey he beats the donkey. Here I will assume the first possibility, which is simpler. $^{25}$

The structure of this possibility, where the sentence with the phonologically reduced VP forms part of the consequent of the conditional, is shown in (33). I am using the theory of Elbourne 2001, 2005, 2013 whereby donkey pronouns are definite determiners with nominal content supplied by NP-deletion: thus we have [he farmer $s_{3}$ ] for he.

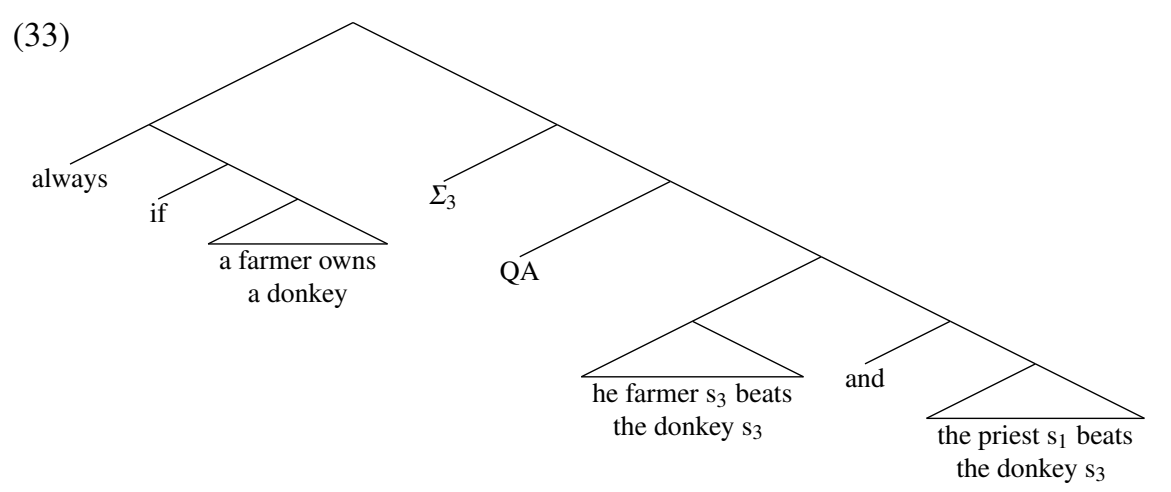

The phrase a farmer owns a donkey will look like this:

(34)

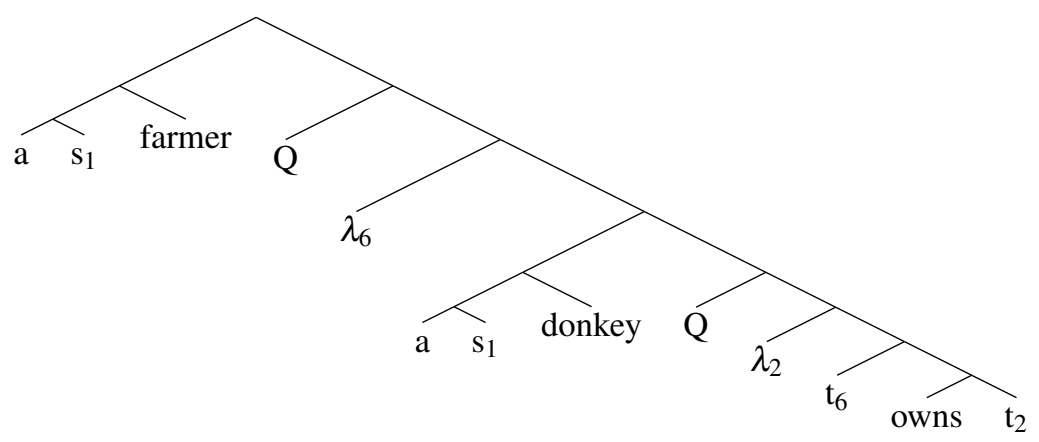

Applying our semantics (Section 4), we obtain the truth-conditions in (35). The situation pronoun $s_{1}$ is mapped to a contextually salient situation $s^{*}$, perhaps a village with surrounding farmland. The structure of the situations posited is shown in (36).

related work, since the current syntactic framework does not use such a distinction. See example (19) and the comment just below it.

${ }^{25}$ See Elbourne 2005, pp. 73-4 for discussion relevant to the second possibility, couched in a related system of situation semantics. 
(35) $\lambda s$. for every minimal situation $s^{\prime}$ such that $s^{\prime} \leq s$ and

there is an individual $x$ and a situation $s^{\prime \prime \prime}$ such that $s^{\prime \prime \prime}$ is a minimal situation such that $s^{\prime \prime \prime} \leq s^{*}$ and $s^{\prime \prime \prime} \leq s^{\prime}$ and $x$ is a farmer in $s^{\prime \prime \prime}$, such that there is a situation $s^{\prime \prime \prime \prime}$ such that $s^{\prime \prime \prime \prime}$ is a minimal situation such that $s^{\prime \prime \prime} \leq s^{\prime \prime \prime \prime}$ and $s^{\prime \prime \prime \prime} \leq s^{\prime}$ and there is an individual $y$ and a situation $s^{\prime \prime \prime \prime \prime \prime}$ such that $s^{\prime \prime \prime \prime \prime \prime}$ is a minimal situation such that $s^{\prime \prime \prime \prime \prime} \leq s^{*}$ and $s^{\prime \prime \prime \prime \prime \prime} \leq s^{\prime \prime \prime \prime}$ and $y$ is a donkey in $s^{\prime \prime \prime \prime \prime}$, such that there is a situation $s^{\prime \prime \prime \prime \prime \prime \prime}$ such that $s^{\prime \prime \prime \prime \prime \prime \prime}$ is a minimal situation such that $s^{\prime \prime \prime \prime \prime} \leq s^{\prime \prime \prime \prime \prime \prime \prime}$ and $s^{\prime \prime \prime \prime \prime \prime \prime} \leq s^{\prime \prime \prime \prime}$ and $x$ owns $y$ in $s^{\prime \prime \prime \prime \prime \prime \prime}$,

there is a situation $s^{\prime \prime}$ such that $s^{\prime \prime}$ is a minimal situation such that $s^{\prime} \leq s^{\prime \prime}$ and $s^{\prime \prime} \leq s$ and $l z z$ is a farmer in $s^{\prime}$ beats in $s^{\prime \prime} l z z$ is a donkey in $s^{\prime}$ and $l z z$ is a priest in $s^{*}$ beats in $s^{\prime \prime} l z z$ is a donkey in $s^{\prime}$

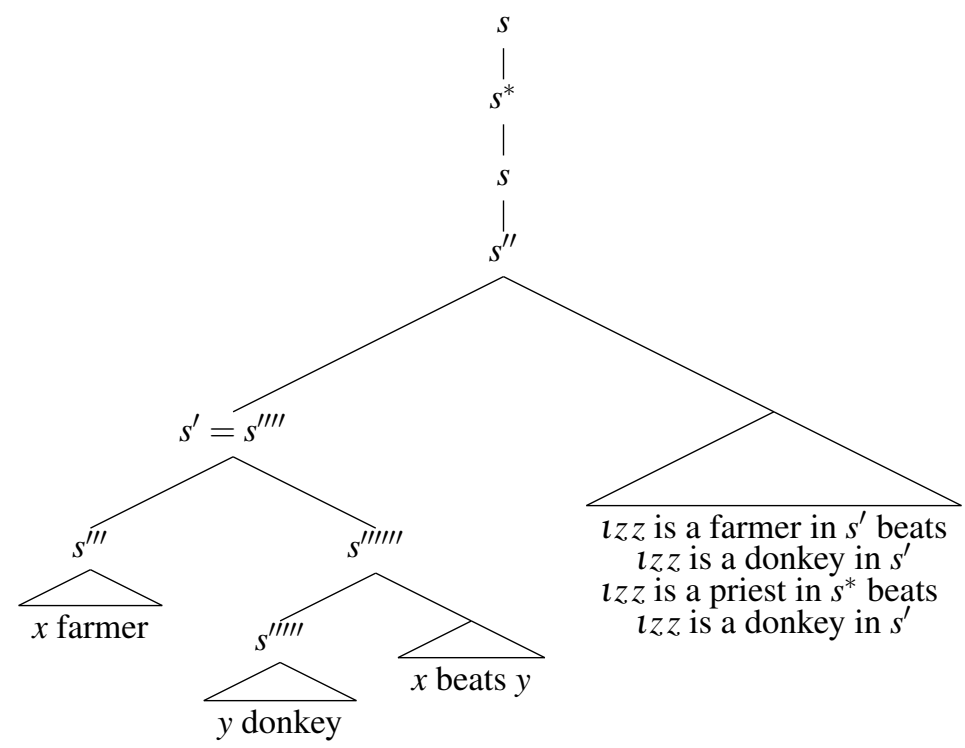

These truth conditions are intuitively accurate. In particular, the priest ends up beating the donkeys of the farmers, since these were the donkeys introduced in the situations $s^{\prime}$. The unwanted sloppy reading is thus avoided.

This is the heart of the argument. Strictly speaking, there is a certain amount of backing and filling that has to take place at this point, since the consequences of various different indexations of situation pronouns and binders have to be worked out. I refer to Elbourne 2013, pp. 183-5 for details; suffice it to say here that none of these manoeuvres allows an unwanted sloppy reading to arise. ${ }^{26,27}$

\footnotetext{
${ }^{26}$ The relevant chapter in Elbourne 2013 also contains discussion of the equivalent sentences with every farmer who... (pp. 185-7) and a response to some counterarguments that have been levelled against this argument (pp. 187-9)

${ }^{27}$ In response to the argument of this section, and the relevant chapter of Elbourne 2013, an anonymous NALS reviewer draws my attention to the fact that a version of (29a) with the final VP not wholly downstressed does not have a sloppy reading:

i. ??In this village, if a farmer owns a donkey, he beats the donkey and the priest beats the DONKEY too

To my ear, however, (i) does not have a strict reading either. In fact the example seems ungrammatical to me. Stressing all or part of the final VP is very infelicitous, presumably because of the close proximity of a lexically identical VP and because of the lack of any clear item with which any of the words in the final VP
} 


\section{The Problem with Bishop Sentences}

A bishop sentence, roughly speaking, is a donkey sentence formed with if or when that meets the following conditions: the two DPs in its protasis are identical; these two DPs, moreover, are the arguments of a verb whose meaning is a symmetrical relation (at least within a relevant domain). Here are some examples:

(37) If a bishop meets a bishop, he blesses him.

(38) If a bishop meets a bishop, the bishop blesses the bishop.

While (37) is more natural, I will be concentrating on the ungainly but revealing (38) in this article. Both examples are understood to entail that if two bishops meet, they bless each other. The question, however, is how they come to have meanings that entail that. In particular, if we suppose, with Frege (1892), Russell (1905) and many others, that the semantics of definite descriptions crucially involves there being exactly one thing that fulfills the descriptive content, it is obscure how the definite descriptions in the apodosis of (38) can be interpreted. We read the bishop; but there is not just one bishop in the entire world; nor can we say straightforwardly that we are dealing with a narrowed domain contributed by a situation pronoun or other means, since the sentence in question is crucially making a generalization about events that feature two bishops; nor, finally, can either occurrence of the bishop mean something like 'the bishop who meets a bishop', since whenever a bishop meets a bishop, the bishop he meets also meets him. (This is why it is important that the first verb meaning be symmetrical on a relevant domain: humans in this case. ${ }^{28}$ ) Bishop sentences like (37), featuring pronouns in the apodosis, were first devised by Hans Kamp to raise a problem for the view that donkey pronouns were interpreted as definite descriptions; they were first reported by Heim (1990).

In Elbourne 2005, I suggested a way of analysing bishop sentences that lets the definite descriptions in (38) be taken at face value. My focus was on (37) and similar sentences, but I analysed donkey pronouns, including those in bishop sentences, as syntactic and semantic definite descriptions. The relevant results are readily transferable to (38), then. The core of the analysis was the observation that the sentence embedded in the protasis of (38), namely (39), has an LF, namely (40), that makes one occurrence of a bishop c-command the other. ${ }^{29}$ This, in turn, gives a non-symmetrical treatment to the two bishops that figure in the truth conditions of this sentence, which, again in the system of Elbourne 2005, turn out to be those in (41). The structure of the situations posited in (41) is given in (42).

(39) a bishop meets a bishop

(40) [[a bishop] $\left[\lambda_{6}\left[[\right.\right.$ a bishop $]\left[\lambda_{2}\left[\mathrm{t}_{6}\right.\right.$ meets $\left.\left.\left.\left.\left.\mathrm{t}_{2}\right]\right]\right]\right]\right]$

(41) $\lambda s$. there is an individual $x$ and a situation $s^{\prime}$ such that $s^{\prime}$ is a minimal situation such that $s^{\prime} \leq s$ and $x$ is a bishop in $s^{\prime}$, such that there is a situation $s^{\prime \prime}$ such that $s^{\prime \prime} \leq s$ and $s^{\prime \prime}$ is a minimal situation such that $s^{\prime} \leq s^{\prime \prime}$ and there is an individual

could contrast. It is not clear to me what lessons can be drawn about (29a) from an ungrammatical example with a different pattern of readings (insofar as the example is interpretable at all).

${ }^{28}$ Of course I can meet an impasse without the impasse thereby meeting me, but that is not a problem unless one demands that the relations in question be symmetrical on the whole of $D_{\mathrm{e}}$.

${ }^{29}$ The structure in (40) differs slightly from the LF that would be given to that sentence in the system of the current article; but I will not take the time now to explain the ways in which the system in Elbourne 2005 differs, both syntactically and semantically, from the system assumed here. Suffice it to say that the system was similar to the one described in the current article, except that it did not employ situation pronouns in the syntax. 
$y$ and a situation $s^{\prime \prime \prime}$, such that $s^{\prime \prime \prime}$ is a minimal situation such that $s^{\prime \prime \prime} \leq s^{\prime \prime}$ and $y$ is a bishop in $s^{\prime \prime \prime}$, such that there is a situation $s^{\prime \prime \prime \prime}$ such that $s^{\prime \prime \prime \prime} \leq s^{\prime \prime}$ and $s^{\prime \prime \prime \prime}$ is a minimal situation such that $s^{\prime \prime \prime} \leq s^{\prime \prime \prime \prime}$ and $x$ meets $y$ in $s^{\prime \prime \prime \prime}$

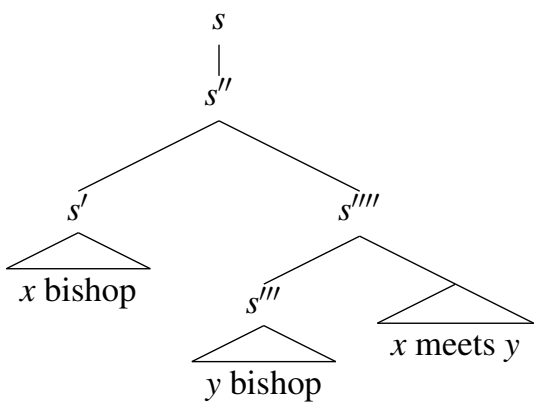

Since the two bishops are not treated symmetrically in the truth conditions of (39), we are presented with a way to differentiate them in truth conditions of (38). For any situation $s$ which is constituted by or contains exactly one structure like that in (42), call the bishop in the least embedded minimal bishop-containing situation in $s$ the 'distinguished' bishop in $s .{ }^{30}$ So in (42) itself, the distinguished bishop is $x$. Now let us assume that implicit content in incomplete definite descriptions can be any salient property. ${ }^{31}$ We can now give (38) the semantics in (43); the structure of the situations posited is in (44).

(43) $\lambda s^{*}$. for every minimal situation $s^{* *}$ such that $s^{* *} \leq s^{*}$ and $[41]\left(s^{* *}\right)=1$, there is a situation $s^{* * *}$ such that $s^{* * *} \leq s^{*}$ and $s^{* * *}$ is a minimal situation such that $s^{* *} \leq$ $s^{* * *}$ and the distinguished bishop in $s^{* * *}$ blesses in $s^{* * *}$ the non-distinguished bishop in $s^{* * *}$

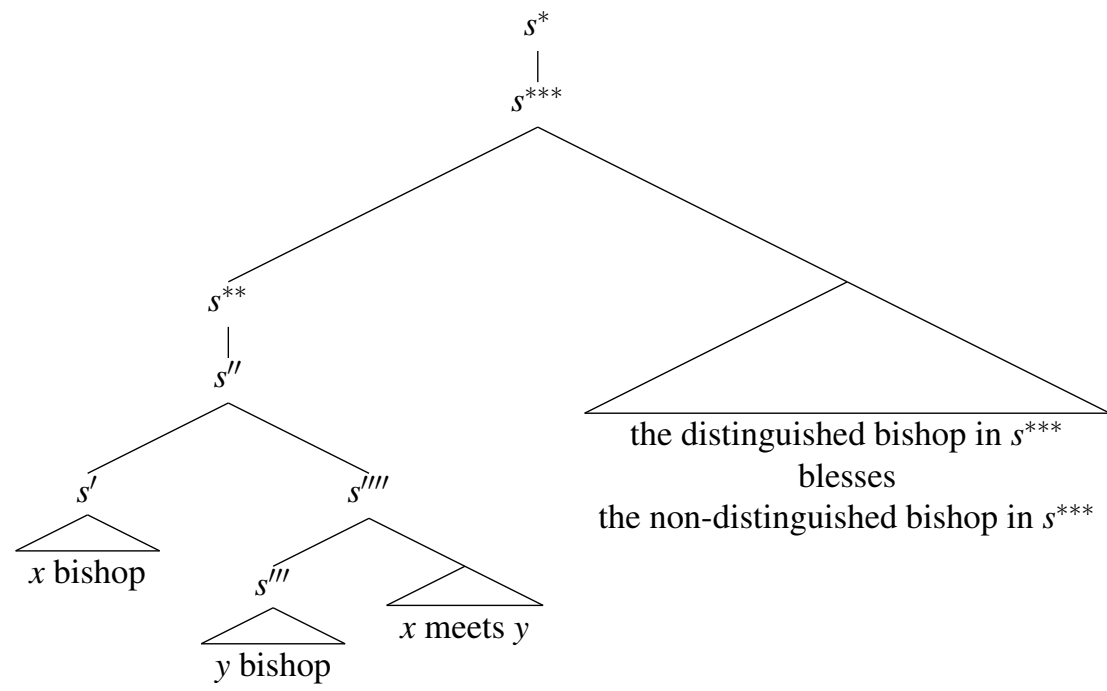

\footnotetext{
${ }^{30}$ See Elbourne 2010 for discussion of some variants of this notion.

${ }^{31}$ I do not assume that we must be conscious of all properties that we use in implicit content, for the plain fact is that we are not. I see no reason why we should not employ a recondite property like 'distinguished', then; the only thing that matters is that it be accessible to the unconscious workings of the language faculty. Note also that, following my (2005) discussion, we are temporarily abandoning the notion of implicit content being supplied only through situation pronouns; we will return to this important point, which is, indeed, the crux of the whole matter.
} 
Note that, due to the definition of distinguished, $x$ is the distinguished bishop in both $s^{* *}$ and $s^{* * *}$ in the above diagram. ${ }^{32}$

Thus we can distinguish the bishops in (38) on the basis of the situation structure imposed by the syntax of the sentence. Note that no means of supplying the necessary implicit properties 'distinguished' and 'non-distinguished' is given in Elbourne 2005; my position there was agnosticism with regard to the question of how implicit content is supplied. The point of the current article is to deal with a problem that arises precisely when this agnosticism is replaced by a particular very restrictive means of supplying implicit content.

What happens, then, when we try to analyse bishop sentences in the system adopted in the current article? Assume that (38) is equipped with a phonologically null quantificational adverb, so that its LF is isomorphic with (26). Then we predict the truth conditions in (45), analogous to those in (27). Once more, $s^{*}$ is a contextually salient situation contributed by a free situation pronoun, as explained in Section 4.3; the structure of the situations posited is shown in (46).

(45) $\lambda s$. for every minimal situation $s^{\prime}$ such that $s^{\prime} \leq s$ and

there is an individual $x$ and a situation $s^{\prime \prime \prime}$ such that $s^{\prime \prime \prime}$ is a minimal situation such that $s^{\prime \prime \prime} \leq s^{*}$ and $s^{\prime \prime \prime} \leq s^{\prime}$ and $x$ is a bishop in $s^{\prime \prime \prime}$, such that there is a situation $s^{\prime \prime \prime \prime}$ such that $s^{\prime \prime \prime \prime}$ is a minimal situation such that $s^{\prime \prime \prime} \leq s^{\prime \prime \prime \prime}$ and $s^{\prime \prime \prime \prime} \leq s^{\prime}$ and there is an individual $y$ and a situation $s^{\prime \prime \prime \prime \prime}$ such that $s^{\prime \prime \prime \prime \prime \prime}$ is a minimal situation such that $s^{\prime \prime \prime \prime \prime} \leq s^{*}$ and $s^{\prime \prime \prime \prime \prime} \leq s^{\prime \prime \prime \prime}$ and $y$ is a bishop in $s^{\prime \prime \prime \prime \prime \prime}$, such that there is a situation $s^{\prime \prime \prime \prime \prime \prime \prime}$ such that $s^{\prime \prime \prime \prime \prime \prime \prime}$ is a minimal situation such that $s^{\prime \prime \prime \prime \prime} \leq s^{\prime \prime \prime \prime \prime \prime \prime}$ and $s^{\prime \prime \prime \prime \prime \prime \prime} \leq s^{\prime \prime \prime \prime}$ and $x$ meets $y$ in $s^{\prime \prime \prime \prime \prime \prime \prime}$,

there is a situation $s^{\prime \prime}$ such that $s^{\prime \prime}$ is a minimal situation such that $s^{\prime} \leq s^{\prime \prime}$ and $s^{\prime \prime} \leq s$ and $\imath z z$ is a bishop in $s^{\prime}$ blesses in $s^{\prime \prime} \imath z z$ is a bishop in $s^{\prime}$

\footnotetext{
${ }^{32}$ An anonymous reviewer raises the following concern about this analysis: "the minimal situations that are introduced as part of the interpretation of the if-clauses of [(37)] and [(38)], in which there is a single bishop, are no longer accessible at the level of the main clause, as part of which the two occurrences of the bishop in [(38)] are to be evaluated.' I believe this objection turns on an overly narrow notion of what it is for the minimal bishop-containing situations to be 'accessible'. It is true that the variable names of those situations are no longer available to be bound when we get to the situations contributed by the main clause. But the truth conditions in (43) do not involve any illicit binding of those variables. The crucial point is that the situations $s^{* * *}$ in (43) contain the minimal bishop-containing situations, as we see in the diagram in (44); and the situations $s^{* * *}$, moreover, have an overall structure such that the predicate distinguished can pick out one of the minimal bishop-containing situations from within them without using a variable name but solely by means of the shape and content of the situations $s^{* * *}$. It might be important to note, in this connection, that the definition of distinguished below (42) makes it clear that the term applies to any situation 'which is constituted by or contains exactly one structure like that in (42)'. (Note the new emphasis.) This means the predicate can apply to the situations $s^{* * *}$.
} 


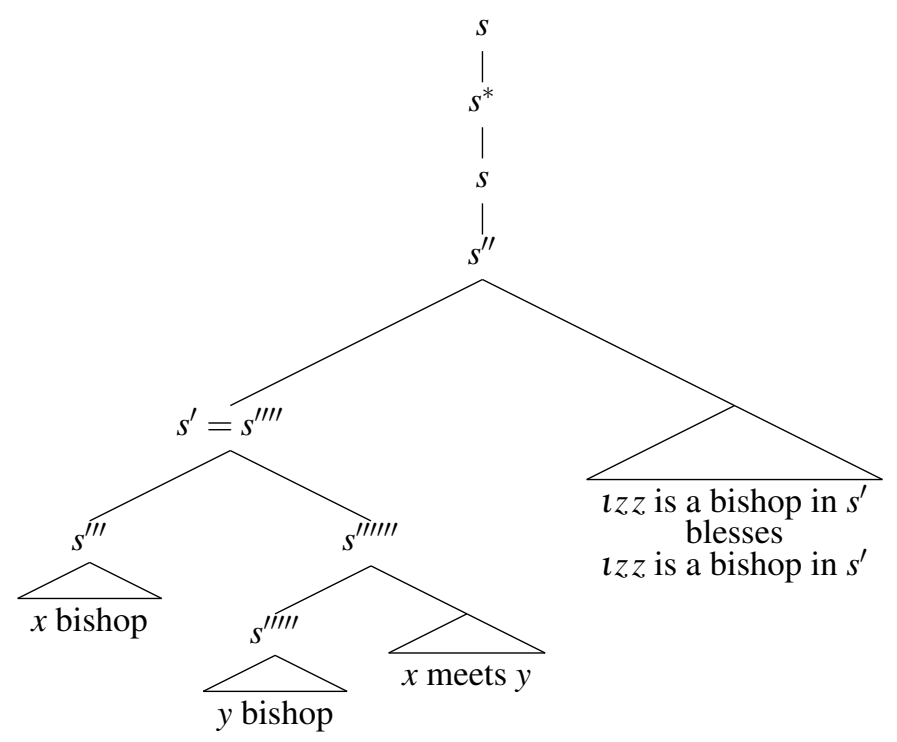

These truth conditions are not intuitively accurate.

They are not intuitively accurate, of course, because they refer twice to the 'the unique bishop in $s^{\prime}$, when in fact there are two bishops in the situations $s^{\prime}$. Nor, unlike in the system of Elbourne 2005, is there any evident way of repairing matters. In the system of Elbourne 2005, when an analogous point was reached, it was possible to posit the use of recondite descriptive content like 'distinguished'; crucially, no restrictions on how descriptive content was introduced into incomplete definite descriptions were assumed in my (2005) monograph. But in the current system, because of the argument summarized in Section 2, I am committed to maintaining that implicit content is introduced into definite descriptions only through situation variables. But the situation variables in the definite descriptions in the current example are fully employed in being bound and achieving covariation. They cannot, in the current system, also provide implicit content. ${ }^{33}$

So there is a tension between the argument in Section 6, which seems to favour using only situation variables for implicit content in definite descriptions, and the bishop data, which seem to favour something more flexible and powerful. This kind of tension would presumably be reproduced in any theory that used only situation variables to deal with implicit content in definite descriptions.

How can this tension be resolved? That is the topic of the next section.

\section{The Solution: Definite Descriptions of Situations}

It is evident that something has got to give and that a revised theory is in the offing. My suggestion is to keep the revised theory as close as possible to the previous theory by maintaining the position that implicit content in definite descriptions is contributed by situation variables; but instead of situation variables tout simple (that is, either referential or bound), I suggest that we are dealing with definite descriptions of situations, where the descriptive content can be contributed in a context-sensitive manner.

\footnotetext{
${ }^{33}$ This problem was pointed out by the eagle-eyed Florian Schwarz (2014) in a review of Elbourne 2013.
} 
Here is a concrete proposal. In place of the situation pronouns of the previous theory, we have structures like this:

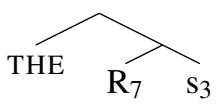

Here $s_{3}$ is a normal situation pronoun of the kind we have seen before. $R_{7}$ is a variable of type $\langle\mathrm{s}, \mathrm{st}\rangle$ whose content can be contextually supplied. And THE is a variant of the definite article designed to deal with arguments of the relevant type:

(48) $\llbracket \mathrm{THE} \rrbracket=\lambda p_{\langle\mathrm{s}, \mathrm{t}\rangle}: \exists ! s p(s)=1 . \operatorname{ss} p(s)=1$

This proposal will entail a few additions and changes to the syntax set out in $\$ 4.1$. Here are the lexical entries of the words that either are or subcategorize for situation variables in the system as set out earlier:

(49) a. $\varepsilon:: \mathrm{S} \mathrm{s}_{i}$

b. the $::=\mathrm{N}=\mathrm{S} \mathrm{D}\langle$-EPP $\rangle$

c. it $::=\mathrm{N}=\mathrm{S} \mathrm{D}\langle$-EPP $\rangle$

d. every $::=\mathrm{S}=\mathrm{N} \mathrm{D}\langle-\mathrm{EPP}\rangle\langle-\mathrm{QR}\rangle$

e. a $::=\mathrm{S}=\mathrm{N} \mathrm{D}\langle-\mathrm{EPP}\rangle\langle-\mathrm{QR}\rangle$

Words like the, it, every and $a$ will now, of course, have to subcategorize for structures like (47). I propose, then, to make those structures be of category S, so that the lexical entries of the determiners can remain unchanged. This will entail a new syntactic category for situation variables. I propose the following lexical entries:

(50) a. THE $::=\mathrm{R} \mathrm{S}$

b. $\mathrm{R}_{i}::=\mathbb{S} \mathrm{R}$

c. $\varepsilon:: \mathbb{S} \mathrm{s}_{i}$

(50a) and (50b) are new, of course; (50c) supplants the previous lexical entry for situation pronouns. By some simple applications of merge, these lexical items will form the following structure, whose head is of category S:

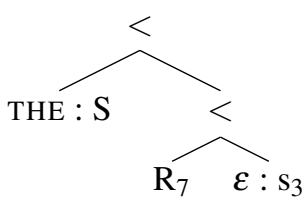

This is the official structure for which (47) is an abbreviation. I will sometimes abbreviate (51) still further as ' $s_{7,3}$ ' and will use analogous abbreviations for other indexings. ${ }^{34}$

This means that (38), repeated here as (52), will have the LF in (53).

(52) If a bishop meets a bishop, the bishop blesses the bishop.

\footnotetext{
${ }^{34}$ The current proposal is reminiscent of, but distinct from, the use of a free variable R to qualify a world variable in Lanier 2014. Lanier $(2014,300)$ does not give a type for his variable $\mathrm{R}$, but it looks from context as if it is meant to map worlds to functions whose type is that of ordinary predicates-perhaps giving a type for $\mathrm{R}$ of $\langle\mathrm{s}, \mathrm{set}\rangle$ or $\langle\mathrm{s}$, est $\rangle$, depending on the view one adopts of the type of predicates in intensional semantics. Lanier's expression [R w] is not taken as an argument by a specially designated definite article.
} 


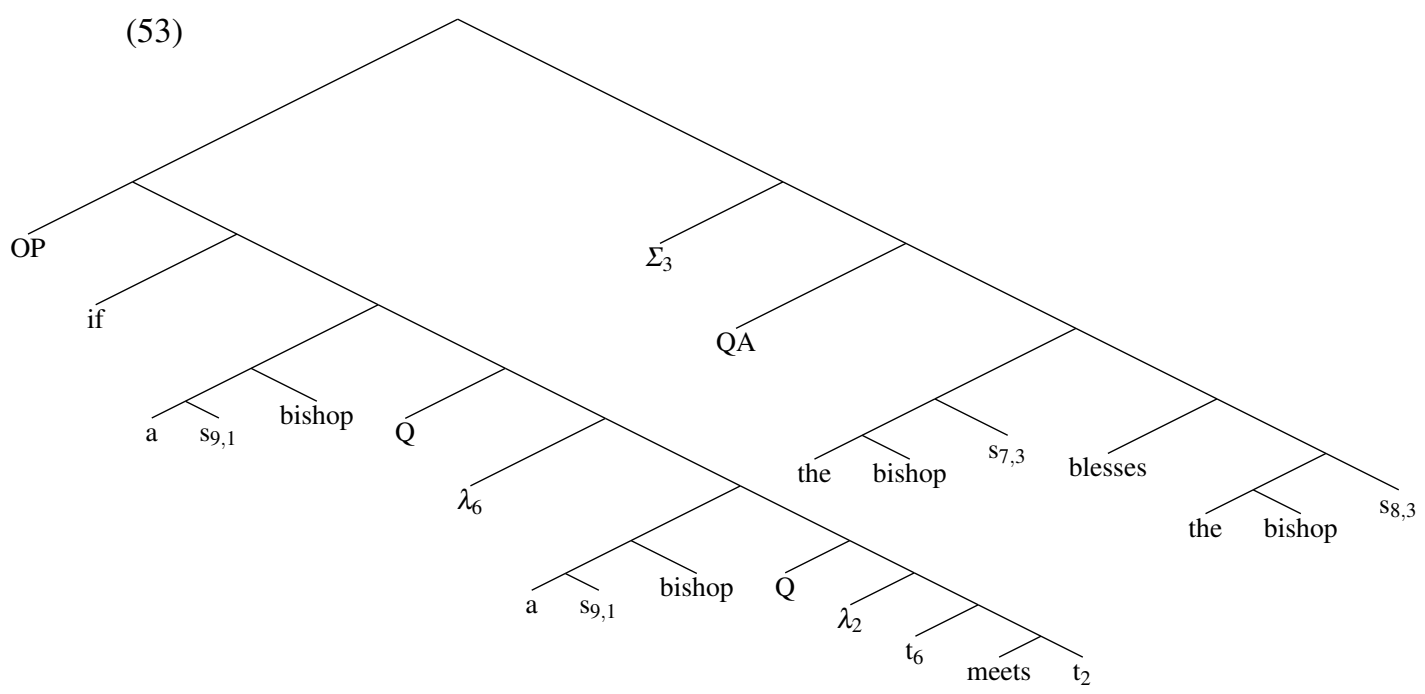

I assume that this structure can be evaluated with respect to a variable assignment $g$ that will include the following mappings:

(54) a. $g(1)=s^{*}$

b. $g(9)=\lambda s \cdot \lambda s^{\prime} \cdot s^{\prime}=s$

c. $g(7)=\lambda s \cdot \lambda s^{\prime} \cdot s^{\prime}$ is the least embedded minimal bishop-containing situation in $s$

d. $g(8)=\lambda s \cdot \lambda s^{\prime} . s^{\prime}$ is the most embedded minimal bishop-containing situation in $s$

$s^{*}$ is a particular restrictor situation, as described in Section 4.3, and $g(7)$ and $g(8)$ are versions of the old distinguished and non-distinguished, respectively. When the function $\lambda s . \lambda s^{\prime} . s^{\prime}=s$ is the value of one of the relation variables in the definite description structures, the semantic value of the whole structure is equivalent, of course, to that of the situation pronoun within it.

Given this LF and variable assignment, the truth conditions of (52) turn out to be those in (55); the structure of the situations posited is that in (56).

(55) $\lambda s$. for every minimal situation $s^{\prime}$ such that $s^{\prime} \leq s$ and

there is an individual $x$ and a situation $s^{\prime \prime \prime}$ such that $s^{\prime \prime \prime}$ is a minimal situation such that $s^{\prime \prime \prime} \leq s^{*}$ and $s^{\prime \prime \prime} \leq s^{\prime}$ and $x$ is a bishop in $s^{\prime \prime \prime}$, such that there is a situation $s^{\prime \prime \prime \prime}$ such that $s^{\prime \prime \prime \prime}$ is a minimal situation such that $s^{\prime \prime \prime} \leq s^{\prime \prime \prime \prime}$ and $s^{\prime \prime \prime \prime} \leq s^{\prime}$ and there is an individual $y$ and a situation $s^{\prime \prime \prime \prime \prime \prime}$ such that $s^{\prime \prime \prime \prime \prime \prime}$ is a minimal situation such that $s^{\prime \prime \prime \prime \prime} \leq s^{*}$ and $s^{\prime \prime \prime \prime \prime} \leq s^{\prime \prime \prime \prime}$ and $y$ is a bishop in $s^{\prime \prime \prime \prime \prime \prime}$, such that there is a situation $s^{\prime \prime \prime \prime \prime \prime \prime}$ such that $s^{\prime \prime \prime \prime \prime \prime \prime}$ is a minimal situation such that $s^{\prime \prime \prime \prime \prime} \leq s^{\prime \prime \prime \prime \prime \prime \prime}$ and $s^{\prime \prime \prime \prime \prime \prime \prime} \leq s^{\prime \prime \prime \prime}$ and $x$ meets $y$ in $s^{\prime \prime \prime \prime \prime \prime \prime}$,

there is a situation $s^{\prime \prime}$ such that $s^{\prime \prime}$ is a minimal situation such that $s^{\prime} \leq s^{\prime \prime}$ and $s^{\prime \prime} \leq s$ and $z z z$ is a bishop in the least embedded minimal bishop-containing situation in $s^{\prime}$ blesses in $s^{\prime \prime} l z z$ is a bishop in the most embedded minimal bishopcontaining situation in $s^{\prime}$ 


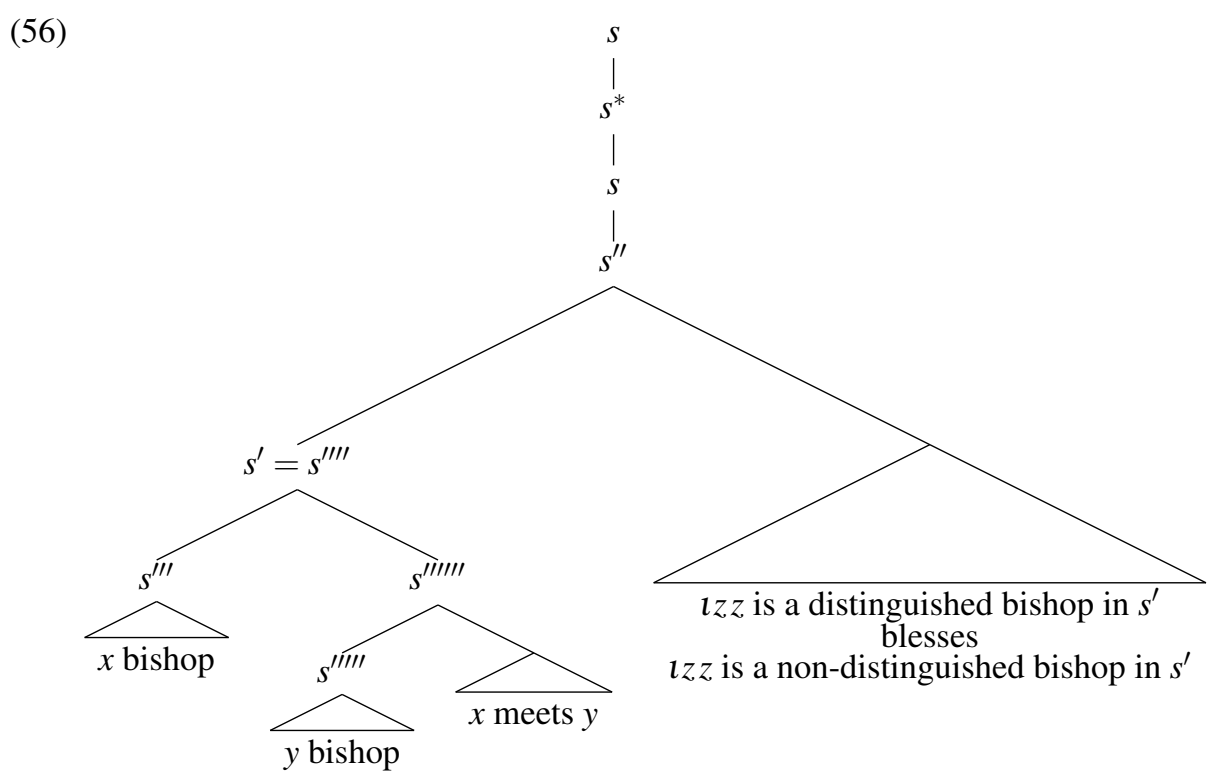

These truth conditions are intuitively accurate.

But this is only half the story. We now have to make sure that this new system is compatible with the data about incompleteness described in Section 2. In particular, we have to check to see that the revised system does not lead to an unwelcome sloppy reading in (29a), repeated here as (57).

(57) In this village, if a farmer owns a donkey, he beats the donkey and the priest beats the donkey too.

(strict, *sloppy)

There will be two parts to the renewed examination of this sentence: showing that the truth conditions arrived at previously can still be arrived at; and showing that the new system, given plausible constraints, does not overgenerate and produce an unattested sloppy reading for this example.

To carry out the first part of our task, let us consider the structure in (58):

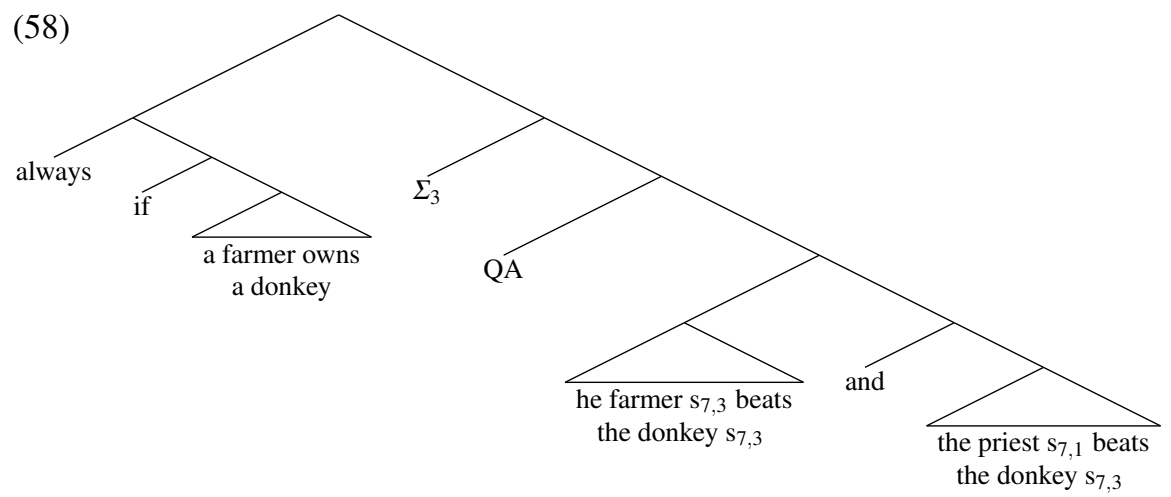

The phrase a farmer owns a donkey will now look like this: 
(59)

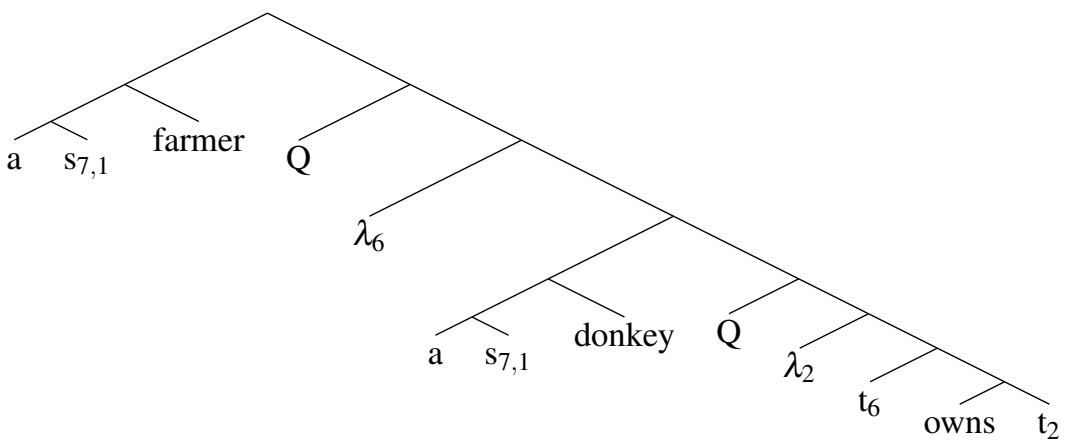

Assume that the sentence is interpreted with respect to a variable assignment $g$ that includes the following mappings.

(60) $\quad$ a. $g(1)=s^{*}$

b. $g(7)=\left[\lambda s \cdot \lambda s^{\prime} \cdot s^{\prime}=s\right]$

Since all the actual situation pronouns (as opposed to situation descriptions) in (58) and (59) have the same indices as the corresponding situation pronouns in (33) and (34), and since in (58) and (59) we have built on top of these pronouns structures that merely take their values and map them to themselves (given the value of 7 in (60) and the meaning of THE), it can be seen that we will obtain the same truth conditions that we saw previously for this example in (35). I repeat them here for ease of reference:

(61) $\lambda s$. for every minimal situation $s^{\prime}$ such that $s^{\prime} \leq s$ and

there is an individual $x$ and a situation $s^{\prime \prime \prime}$ such that $s^{\prime \prime \prime}$ is a minimal situation such that $s^{\prime \prime \prime} \leq s^{*}$ and $s^{\prime \prime \prime} \leq s^{\prime}$ and $x$ is a farmer in $s^{\prime \prime \prime}$, such that there is a situation $s^{\prime \prime \prime \prime}$ such that $s^{\prime \prime \prime \prime}$ is a minimal situation such that $s^{\prime \prime \prime} \leq s^{\prime \prime \prime \prime}$ and $s^{\prime \prime \prime \prime} \leq s^{\prime}$ and there is an individual $y$ and a situation $s^{\prime \prime \prime \prime \prime \prime}$ such that $s^{\prime \prime \prime \prime \prime \prime}$ is a minimal situation such that $s^{\prime \prime \prime \prime \prime} \leq s^{*}$ and $s^{\prime \prime \prime \prime \prime} \leq s^{\prime \prime \prime \prime}$ and $y$ is a donkey in $s^{\prime \prime \prime \prime \prime}$, such that there is a situation $s^{\prime \prime \prime \prime \prime \prime \prime}$ such that $s^{\prime \prime \prime \prime \prime \prime \prime}$ is a minimal situation such that $s^{\prime \prime \prime \prime \prime} \leq s^{\prime \prime \prime \prime \prime \prime \prime}$ and $s^{\prime \prime \prime \prime \prime \prime \prime} \leq s^{\prime \prime \prime \prime}$ and $x$ owns $y$ in $s^{\prime \prime \prime \prime \prime \prime \prime}$,

there is a situation $s^{\prime \prime}$ such that $s^{\prime \prime}$ is a minimal situation such that $s^{\prime} \leq s^{\prime \prime}$ and $s^{\prime \prime} \leq s$ and $l z z$ is a farmer in $s^{\prime}$ beats in $s^{\prime \prime} l z z$ is a donkey in $s^{\prime}$ and $l z z$ is a priest in $s^{*}$ beats in $s^{\prime \prime} l z z$ is a donkey in $s^{\prime}$ 
(62)

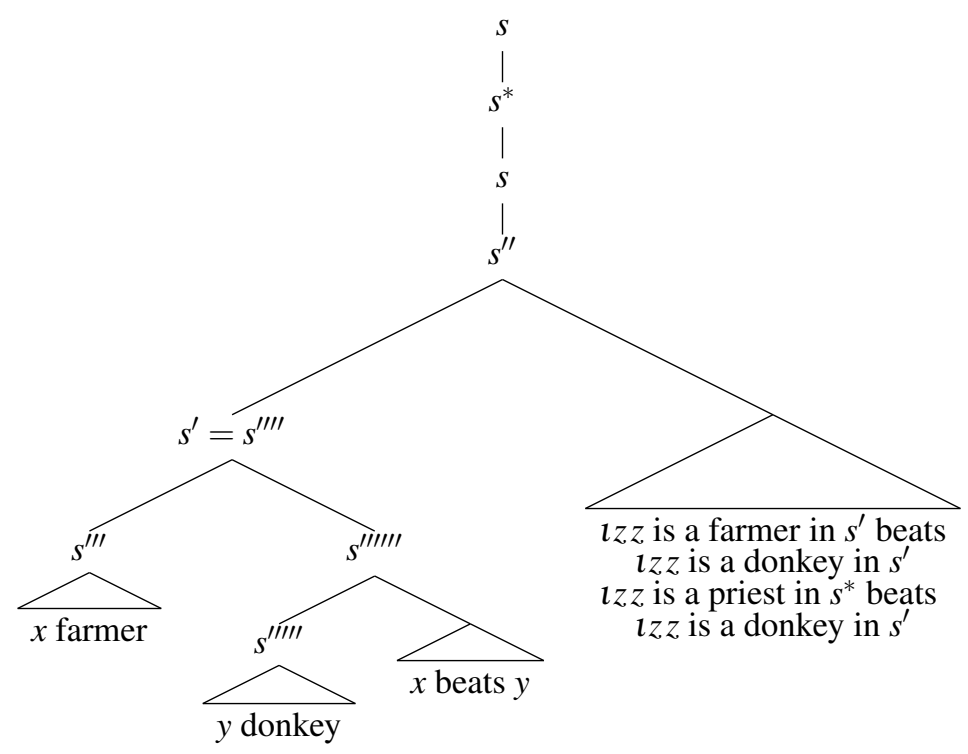

It is possible that the function $\left[\lambda s . \lambda s^{\prime} . s^{\prime}=s\right]$ is some kind of default value that will be assumed in the absence of any reason to assume another one, although I will not try to implement this intuition formally.

Now for the trickier part. It is probably impossible to show conclusively that no combination of indexing and assignment will produce a sloppy reading for this sentence. But the following considerations, I think, make it very unlikely that such a combination could be found.

I wish to start by considering limits on the possible indexings that the variables in our sentence can receive. In particular, I propose that, given the kind of reading we are dealing with (a donkey-anaphoric one), the following indexing represents a sensible limit on the variation:

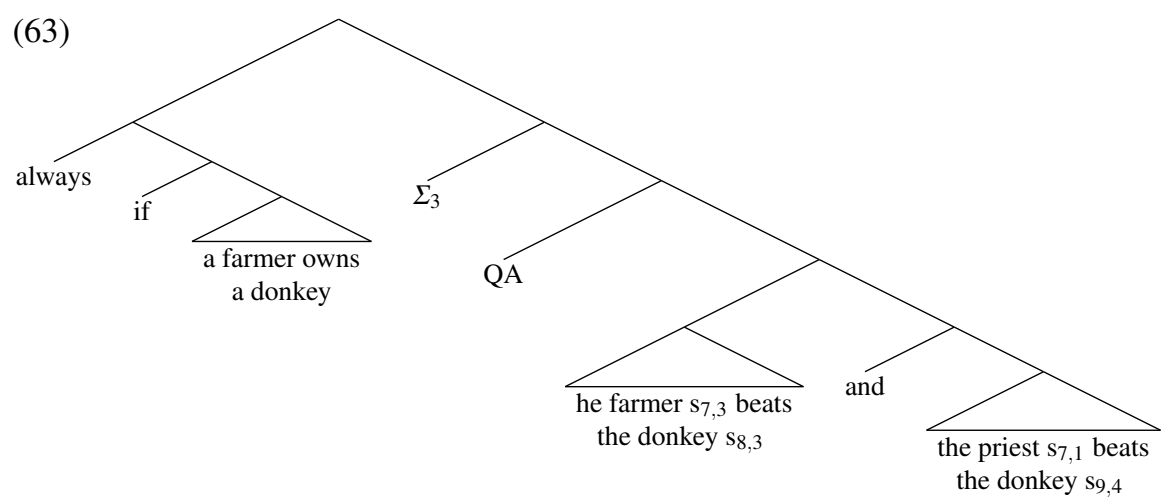


(64)

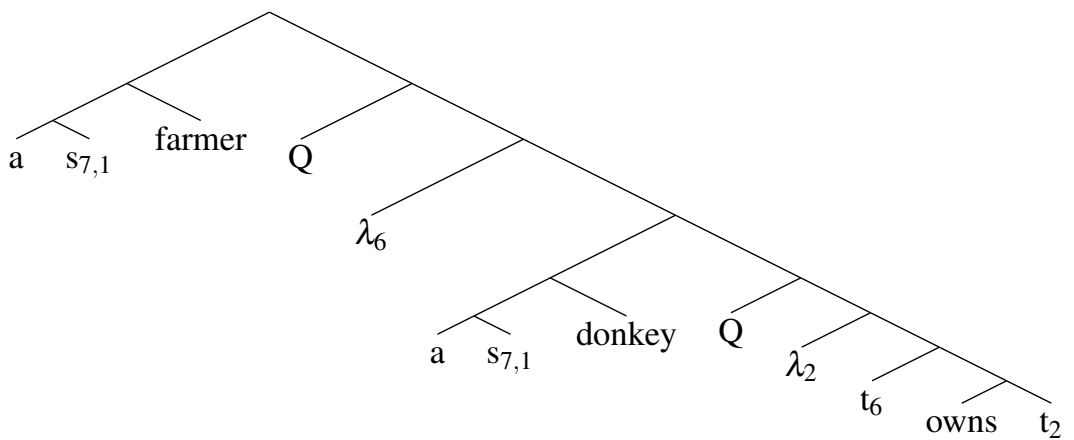

I wish to review this indexing while applying the following mappings, since they are necessary to capture the kind of reading that we have in mind for the sentence:

$$
\begin{aligned}
& \text { a. } g(1)=s^{*} \\
& \text { b. } g(7)=\lambda s \cdot \lambda s^{\prime} \cdot s^{\prime}=s
\end{aligned}
$$

We find situation descriptions $\mathrm{s}_{7,1}$ on a farmer, a donkey and the priest. These are perfectly straightforward, in that they just restrict the claim being made to the farmers, donkeys and priests (the unique priest, actually) to be found in a contextually salient situation $s^{*}$. The kind of reading that we are interested in for this sentence dictates these indexings, or trivial alphabetic variants; any plausible indexing for it would have to involve these indexings and the mappings in (65).

This leaves the following indexings:

(66) a. he farmer $\mathrm{s}_{7,3}$

b. the donkey $\mathrm{s}_{8,3}$

c. the donkey $\mathrm{s}_{9,4}$

The indexing on the situation description $\mathrm{s}_{7,3}$ that accompanies he farmer is straightforward. We are interested in a donkey-anaphoric reading of the sentence, which means that the surface pronoun he is a donkey anaphor. As remarked in Section 2, I am following the theory promulgated in Elbourne 2001 and related work, whereby donkey pronouns are definite articles whose NP complements have been deleted by compulsory NP-deletion. Covariation in such structures is brought about by situation variables, according to the relevant theory. Given the current instantiation of that theory, which has situation binders like $\Sigma_{3}$ in the syntax (following Heim (1990) and Büring (2004)), we need to have the situation pronoun in $\mathrm{s}_{7,3}$ be coindexed with the situation binder in question. Hence the index 3 . We could possibly explore indices other than 7 to put on the variable $R$ on this occasion (i.e. we could explore relations other than $\left.\left[\lambda s . \lambda s^{\prime} . s^{\prime}=s\right]\right)$, but farmers are not really the issue here, since they do not figure in the sentence after this one occurrence. In order to explore strict and sloppy readings, the interpretation of the two occurrences of the donkey is what we need to concentrate on. We just need some way of picking out the right farmers on this one occasion, then; and the situation description $\mathrm{s}_{7,3}$, with the relation $\left[\lambda s \cdot \lambda s^{\prime} . s^{\prime}=s\right]$, is the most straightforward way of doing this.

Let us move on to consider the situation description $\mathrm{s}_{8,3}$, which accompanies the first occurrence of the donkey. Since this is the first occurrence of the donkey and we want a donkey-anaphoric reading of the sentence, we must, given the current theory, have an index 3 on the situation pronoun here in order to achieve appropriate covariation, given that the situation binder is $\Sigma_{3}$. (I will not explore trivial alphabetic variants.) But we will need to think about the interpretation of the $R$ variable. The easiest way to 
bring about a donkey-anaphoric reading is to have this variable too denote the function $\left[\lambda s . \lambda s^{\prime} . s^{\prime}=s\right]$ :

$$
\text { (67) } g(8)=\left[\lambda s \cdot \lambda s^{\prime} \cdot s^{\prime}=s\right]
$$

But we might want to consider other possible values for the index 8 , to see if they would help the cause of a sloppy reading. Note that the index 8 on this occurrence of $R$ is free and not identical to the index on anything else in the structure. We are not prejudicing anything if we leave it as 8 , then, and leave open the possibility that it could have other values than the one shown in (67).

Finally, let us consider the situation description $s_{9,4}$ that accompanies the second occurrence of the donkey. Here we are not still engaged, as it were, in bringing about a donkey-anaphoric reading; so there is no reason to insist that the index on the situation pronoun be 3 . The index 9 on this occurrence of $R$, like the occurrence of 8 that we just examined, is free and not identical to any index anywhere else; we will naturally want to see if any value for it might help bring about a sloppy reading.

In sum, we should consider values for the index on the situation pronoun for the second occurrence of the donkey and values for the indices on the relation variables for both the first and second occurrences of that phrase.

Here is another way of looking at this. Consider the following schema for truth conditions for (63).

(68) $\lambda s$. for every minimal situation $s^{\prime}$ such that $s^{\prime} \leq s$ and a man owns a donkey in $s^{\prime}$, there is a situation $s^{\prime \prime}$ such that $s^{\prime \prime}$ is a minimal situation such that $s^{\prime} \leq s^{\prime \prime}$ and $s^{\prime \prime} \leq s$ and $t z z$ is a farmer in $s^{\prime}$ beats in $s^{\prime \prime} l z z$ is a donkey in $l s s \ldots s^{\prime}$ and $t z z$ is a priest in $s^{*}$ beats in $s^{\prime \prime} \imath z z$ is a donkey in $t s s \ldots$

This is a simplified version of (61), except that the situation descriptions we are interested in are now spelled out, in gappy form, with iota operators. The question we must now consider is whether there is any way of legitimately filling in the ellipses in (68) in such a way that we obtain a normal donkey-anaphoric reading in the first conjunct of and and a sloppy reading (the priest being assumed to own and asserted to beat his own donkey) in the second conjunct. The proposed completions must be capable of emerging from the value of a variable of type $\langle\mathrm{s}, \mathrm{st}\rangle$ in the case of the first ellipsis and from a combination of a variable of that type and a situation pronoun in the case of the second ellipsis. ${ }^{35}$

To start us off, here is one obvious way of achieving donkey anaphora and a sloppy reading subject to the above constraints. We fill in the ellipses in the latter part of (68) as follows:

(69) $\lambda s$. for every minimal situation $s^{\prime}$ such that $s^{\prime} \leq s$ and a man owns a donkey in $s^{\prime}$, there is a situation $s^{\prime \prime}$ such that $s^{\prime \prime}$ is a minimal situation such that $s^{\prime} \leq s^{\prime \prime}$ and $s^{\prime \prime} \leq s$ and $\imath z z$ is a farmer in $s^{\prime}$ beats in $s^{\prime \prime} t z z$ is a donkey in $\underline{t s s=s^{\prime}}$ and $\imath z z$ is a priest in $s^{*}$ beats in $s^{\prime \prime} l z z$ is a donkey in $\underline{t s s=s^{* *}}$

Here it is to be understood that $s^{* *}$ is a situation containing no donkeys other than the donkey of the priest. We could easily achieve the truth conditions in (69) by assuming the following mappings:

$$
\begin{aligned}
& \text { a. } g(8)=\lambda s \cdot \lambda s^{\prime} \cdot s^{\prime}=s \\
& \text { b. } g(9)=\lambda s \cdot \lambda s^{\prime} \cdot s^{\prime}=s
\end{aligned}
$$

\footnotetext{
${ }^{35}$ Lest there be any confusion, let it be noted that I am here using the term ellipsis to refer to the punctuation mark ('...') of that name; I am not trying to talk about NP-deletion or anything similar.
} 
c. $g(4)=s^{* *}$

What, then, is wrong with this?

The answer, I propose, is that this interpretation is illicit because of the constraints operative on downstressed material. Recall that (57), repeated here as (71), has its final VP downstressed or phonologically reduced, as indicated by the small italics:

(71) In this village, if a farmer owns a donkey, he beats the donkey and the priest beats the donkey too.

(strict, *sloppy)

The basic intuition that a number of authors (Rooth 1992, Schwarzschild 1999, Fox 2000) have worked with is that downstressed material must contribute old information, in that its meaning must be identical to or entailed by the meaning of an antecedent phrase. ${ }^{36}$ When we look at it in this light, we can readily appreciate why (71) cannot have the interpretation that would be given to it by (70). We are talking about the two VPs pronounced beats the donkey. Using the variable names in (69), the first such VP denotes, roughly speaking, the property of beating in the situations $s^{\prime \prime}$ the unique donkey in the corresponding situations $s^{\prime}$; whereas the second such VP denotes, roughly speaking, the property of beating in the situations $s^{\prime \prime}$ the unique donkey in the situation $s^{* *}$, where $s^{* *}$ is distinct from any of the situations $s^{\prime}$. (Assume that the priest is not also a farmer.) It is clear, then, that the meaning of the antecedent VP is not identical to and does not plausibly entail the meaning of the downstressed VP. So the conditions on downstressed material are not met and the interpretation in question is not possible.

I think that any theory of the semantics of downstressing should predict this result (by being modified if necessary). But it may be of some interest to show that Schwarzschild's (1999) theory already predicts it. I will now attempt to demonstrate this.

Schwarzschild's (1999) theory is based around the notion of F-marking in the sense of Selkirk (1995): an intonationally prominent word is marked with an F-feature and rules that need not concern us now license the projection of that feature to larger phrases. We are here concerned with constituents that are not F-marked, which are, in other words, phonologically reduced. Here is Schwarzschild's $(1999,150)$ condition on non-F-marked constituents:

(72) Non-F-marked constituents must be GIVEN.

The definition of GIVEN (Schwarzschild 1999, 152) is in (73). It relies on the definition of Existential Type Shift in (74) and the definition of Existential F-Closure in (75) (Schwarzschild 1999, 152). ${ }^{37}$

\footnotetext{
${ }^{36}$ Umbach $(2001,263-4)$, in particular, says that deaccented definite descriptions are 'given' and that 'Given definites, in the sense employed here, are identity anaphors referring to a discourse referent which has already been introduced.' She gives ample evidence to support this for relatively simple cases involving reference to a unique referent; but she does not investigate cases of covarying definite descriptions or attempted sloppy identity involving definite descriptions.

${ }^{37}$ Note that I am here relying on Schwarzschild's formal versions of his definitions, not the informal versions that are, perhaps, more frequently quoted. The reason for this, briefly, is that the crucial VPs whose denotations we will be comparing contain variables that are locally free (although some of them are bound in the larger structure by a situation binder $\Sigma_{i}$ ). The condition in (73) about the relevant entailment holding for all variable assignments $g$ provides a neat way to deal with these locally free variables that seems to predict the right results in this case (and in others too, of course). The informal versions of the definitions (Schwarzschild 1999, 150) do not contain any such provision. I have made some small changes to Schwarzschild's definitions to suit my personal tastes and current conventions: the most substantive one is that I have used $\langle\mathrm{s}, \mathrm{t}\rangle$ as the type of propositions in (74), as opposed to Schwarzschild's t. I have also corrected a misprint in Schwarzchild's (1999) article that might be confusing for readers new to this area: in definition (26b) on page 152 of that article, the last omega should be a ' $w$ '.
} 


\section{(73) Definition of Given}

An expression $E$ counts as GIVEN iff it has an antecedent $A$ and

a. if the semantic type of $E$ is e, $\forall\langle\mathrm{w}, \mathrm{g}\rangle \exists h\left(\llbracket \mathrm{A} \rrbracket^{g}=\llbracket \mathrm{E} \rrbracket^{g, h}\right)$;

b. if the semantic type of $E$ is conjoinable, $\forall\langle\mathrm{w}, \mathrm{g}\rangle \exists h\left(\operatorname{ExClo}\left(\llbracket \mathrm{A} \rrbracket^{g}\right)(w) \rightarrow \operatorname{ExClo}\left(\llbracket \mathrm{E} \rrbracket^{g, h}\right)(w)\right)$

c. $\langle s, t\rangle$ is a conjoinable type. If $\mathrm{b}$ is a conjoinable type, then so is $\langle a, b\rangle$, for any type a.

(74) Definition of Existential Type Shift (ExClo)

a. If $\omega \in D_{\langle s, t\rangle}$, then $\operatorname{ExClo}(\omega)=\omega$.

b. For any coinjoinable type $\langle\mathrm{a}, \mathrm{b}\rangle$ :

If $\omega \in D_{\langle\mathrm{a}, \mathrm{b}\rangle}$, then $\operatorname{ExClo}(\omega)=\lambda w \exists u_{a}(\operatorname{ExClo}(\omega(u))(w))$.

(75) Existential F-Closure

a. If $\alpha$ is F-marked with index $F_{n}$, then:

i. $\llbracket[\alpha]_{\mathrm{F}_{\mathrm{n}}} \rrbracket^{g, h}=h\left(F_{n}\right)$;

ii. $\llbracket[\alpha]_{\mathrm{F}_{\mathrm{n}}} \rrbracket^{g}=\llbracket \alpha \rrbracket^{g}$.

b. If $\alpha$ has no F-marking, then:

i. if $\alpha$ is not complex, $\llbracket \alpha \rrbracket^{g, h}=\llbracket \alpha \rrbracket^{g}$;

ii. if $\alpha$ has components $\beta_{1} \ldots \beta_{n}$, then $\llbracket \alpha \rrbracket^{g, h}$ is the result of applying the semantic rule for $\alpha$ to $\llbracket \beta_{1} \rrbracket^{g, h} \ldots \llbracket \beta_{n} \rrbracket^{g, h}$.

The definition in (75) makes use of a special variable assignment $h$, in addition to the normal one $g$; the purpose of $h$ is to assign meanings to indexed F-markings (Kratzer 1991). With the help of the ' $\exists h$ ' in (73b), we are enabled by this device to do something equivalent to existentially quantifying over F-marked positions.

Readers wanting to get a feel for the calculations mandated by these definitions might like to verify that [GREEN $\mathrm{F}_{1}$ apple] counts as GIVEN in a context in which the constituent [apple] has been uttered. The calculation in this case is shown in abbreviated form in (76):

$$
\begin{aligned}
\text { a. } & \forall\langle\mathrm{w}, \mathrm{g}\rangle \exists h\left(\operatorname{ExClo}\left(\llbracket \text { apple } \rrbracket^{g}\right)(w) \rightarrow\right. \\
& \left.\operatorname{ExClo}\left(\llbracket \operatorname{green}_{\mathrm{F}_{1}} \text { apple } \rrbracket^{g, h}\right)(w)\right) \\
\text { b. } & \forall\langle\mathrm{w}, \mathrm{g}\rangle \exists h(\operatorname{ExClo}(\lambda x . \lambda s \cdot x \text { is an apple in } s)(w) \rightarrow \\
& \operatorname{ExClo}\left(\lambda x \cdot \lambda s \cdot \llbracket \operatorname{green}_{\mathrm{F}_{1}} g^{g, h}(x)(s)=1\right. \\
& \left.\left.\& \llbracket \operatorname{apple} \rrbracket^{g, h}(x)(s)=1\right)(w)\right) \\
\text { c. } & \forall\langle\mathrm{w}, \mathrm{g}\rangle \exists h(\exists x x \text { is an apple in } w \rightarrow \\
& \left.\exists x\left(h\left(\mathrm{~F}_{1}\right)(x)(w)=1 \& x \text { is an apple in } w\right)\right)
\end{aligned}
$$

We need this last formula to be true, then, if [GREEN $\mathrm{F}_{1}$ apple] is to be GIVEN in the context in question. As we can tell, this is the case. The formula could be verified trivially, for example, by an assignment $h$ that maps $F_{1}$ to the property of being an apple.

Let us now return to the truth conditions in (69), repeated here as (77), which encode an unwelcome sloppy reading.

(77) $\lambda s$. for every minimal situation $s^{\prime}$ such that $s^{\prime} \leq s$ and a man owns a donkey in $s^{\prime}$, there is a situation $s^{\prime \prime}$ such that $s^{\prime \prime}$ is a minimal situation such that $s^{\prime} \leq s^{\prime \prime}$ and $s^{\prime \prime} \leq s$ and $\imath z z$ is a farmer in $s^{\prime}$ beats in $s^{\prime \prime} l z z$ is a donkey in $\underline{\imath s s=s^{\prime}}$ and $t z z$ is a priest in $s^{*}$ beats in $s^{\prime \prime} \iota z z$ is a donkey in $\underline{\imath s s=s^{* *}}$

The situation $s^{* *}$, recall, is a situation containing the donkey of the priest and no others. The idea was that we arrive at these truth conditions by using the two VPs in (63) 
pronounced beats the donkey, interpreted by means of the mapping in (70). The two VPs are repeated here in (78) and (70) is repeated as (79). Note that I have included F-marking on the occurrence of beats in the first VP, since beating has not previously been mentioned in (63) (whereas donkeys have).

(78) $\left[\mathrm{vP}_{\mathrm{P}}\right.$ beats $\mathrm{s}_{\mathrm{F}_{1}}$ the donkey $\left.\mathrm{s}_{8,3}\right] \ldots$ [vP beats the donkey $\left.\mathrm{s}_{9,4}\right]$

(79) a. $g(8)=\lambda s \cdot \lambda s^{\prime} \cdot s^{\prime}=s$

b. $g(9)=\lambda s \cdot \lambda s^{\prime} \cdot s^{\prime}=s$

c. $g(4)=s^{* *}$

Now in light of Schwarzschild's theory, we will immediately protest that having two separate indices 8 and 9 for the relation variables in the situation descriptions is putting unnecessary difficulties in the way of this kind of analysis. In order allow these structures to emerge unscathed from the universal quantification over variable assignments in (73b), we will at the very least use the same index in both these places - 8, say, with the same interpretation it has in (79). This means that we should change the VPs and the relevant mappings to the following:

(80) [vp beats $\mathrm{F}_{\mathrm{F}_{1}}$ the donkey $\mathrm{s}_{8,3}$ ] . . [vP beats the donkey $\mathrm{s}_{8,4}$ ]

(81) a. $g(8)=\lambda s \cdot \lambda s^{\prime} \cdot s^{\prime}=s$

b. $g(4)=s^{* *}$

But note that, crucially, we cannot eliminate the difference between the indices 3 and 4 if we are to arrive at the interpretation we are interested in. This is because we need the index 3 to be bound by the higher situation binder $\Sigma_{3}$ in (63) in order to bring about the covarying interpretation for the donkeys of the farmers; and we need a distinct situation variable, indexed 4 in this case, to pick out the donkey of the priest. Having the index 3 in the place of the current index 4 will have the priest beating the donkeys of the farmers.

This means that the second VP in (80) will not be GIVEN, even though it has a VP antecedent. When we perform the calculation to verify this based on (73), using the first VP as antecedent, we arrive at the following claim:

(82) $\forall\langle\mathrm{w}, \mathrm{g}\rangle \exists h(\exists x x$ beats in $w \imath z z$ is a donkey in $\imath s[[g(8)](g(3))](s)=1 \rightarrow$ $\exists x x$ beats in $w \imath z z$ is a donkey in $t s[[g(8)](g(4))](s)=1)$

But of course, given that it involves universal quantification over assignments $g$, this claim is not true, since there will be assignments that map 3 and 4 to different things.

As I said, the difference between the indices 3 and 4 in the relevant LF is ineliminable, given the reading we are currently interested in. That reading is the sloppy reading, of course. Turning now to the strict reading, we have already seen in (58) that this reading can be brought about by means of an indexing that gives the same indices to the corresponding positions in the two VPs. Here are those two VPs, with some plausible F-marking added in the first one.

(83) $\left[\mathrm{vP}_{\text {beats }} \mathrm{F}_{1}\right.$ the donkey $\left.\mathrm{s}_{7,3}\right] \ldots$ [vp beats the donkey $\mathrm{s}_{7,3}$ ]

A calculation precisely parallel to the one that gave us (82) will yield up the following claim for this case:

(84) $\forall\langle\mathrm{w}, \mathrm{g}\rangle \exists h(\exists x x$ beats in $w \imath z z$ is a donkey in $\imath s[[g(7)](g(3))](s)=1 \rightarrow$ $\exists x x$ beats in $w \imath z z$ is a donkey in $t s[[g(7)](g(3))](s)=1)$

Since the two expressions on either side of material implication do not differ in this case, the claim is true, meaning that the second VP in GIVEN. 
So the attempt to secure a sloppy reading for (71) that we have been investigating (beginning with the truth conditions in (69)) does not succeed. I hope it is evident by now that no attempt to secure a sloppy reading will succeed which has different indices on the variables involved. As soon as the indexing differs, the structures run afoul of the definition of GIVENness in (73)..$^{38,39}$

Any attempt to secure a sloppy reading, then, must have the same indices on the situation descriptions in antecedent phrase and downstressed phrase. We should be dealing with the indexing in (83) or an alphabetic variant. Furthermore, in order to bring about the appropriate covariation in the antecedent phrase, we need the index 3 on the situation variable there to be bound by the higher binder $\Sigma_{3}$. This means, of course, that the index 3 on the situation variable in the downstressed phrase will be bound by that binder too, given the structure in (58). So the only flexibility we have left is in the interpretation of $R$, which is to say the value of the index 7 in (83).

At this point I fear I must simply say that I cannot think of any value for this index that would give an appropriate covarying reading for the antecedent and a sloppy reading for the downstressed phrase. What would such a value be like? One natural thought to have at this stage is that the situation description in each VP should have a semantic value something like ' $i s$ s contains a donkey belonging to him', where 'him' would be bound (roughly speaking) by he in the first VP and by the priest in the second; this would imply a value for $R_{7}$ of something like $\left[\lambda s . \lambda s^{\prime} . s^{\prime}\right.$ contains a donkey belonging to him]. But this is not possible in the current system, since the value of $R_{7}$ must be something that is in itself not context sensitive. $R_{7}$, being a free variable, is context sensitive; but in assigning it a value we must resolve that context sensitivity. But the 'him' posited by the current train of thought is an element that would be context sensitive; to be precise, it would be bound by one thing in one occurrence and by another thing in another occurrence. So this tempting and natural thought goes nowhere. The only other possibility that presents itself is some kind of radically disjunctive approach: that is, we could try to posit a single value for $R_{7}$ that would include different possibilities based on different circumstances; it would have the effect of contributing a suitable value (perhaps $\left[\lambda s . \lambda s^{\prime} . s^{\prime}=s\right]$ ) in the antecedent and a different value (perhaps $\left.\left[\lambda s . \lambda s^{\prime} . s^{\prime}=s^{* *}\right]\right)$ in the downstressed phrase. But what differing circumstances could trigger these different, presumably disjunctively listed, contributions? The most natural thing to suggest, in the case of a relation variable that takes one argument (before the resulting predicate is taken as an argument by something else), is that the different contributions are triggered by taking different things as arguments; but that will not work here, since the relation variable takes the same thing (the value of the index 3 , in our current set-up) as argument each time. Could the different values be triggered by whether farmers or priests have just been mentioned? It is not clear how to cash out such an intuition formally, since there are no 'mentions' in the relevant calculations

\footnotetext{
${ }^{38} \mathrm{An}$ anonymous reviewer summarizes this argument as follows. 'So it is because the GIVENness of the destressed beats the donkey is obligatory that its Existential Closure must be entailed by the Existential Closure of the (LF of the) first occurrence of beats the donkey; and that requires that the two occurrences of the donkey be coreferential and that their coreferentiality be formally secured. In other words, the need to interpret the destressed phrase as GIVEN forces the interpretation process to identify the situations in the manner indicated.' If we change 'coreferential' to 'covalued', since we are dealing with a covarying interpretation, I think that this is an excellent way of putting things.

${ }^{39}$ It seems, in general, that Schwarzschild's system will prohibit what we might call accidental covaluation when one pronoun is in an antecedent and another, covalued but contra-indexed, pronoun is in the corresponding downstressed material. It sounds like this might have consequences for our theory of binding, broadly construed; but I will not attempt to explore them here.
} 
of truth conditions. One could possibly introduce formal machinery to keep track of topics, as in the 'centering theory' of Grosz et al. (1995); but then again one could also refrain from doing so. Any attempt along these lines to argue that a sloppy reading would be generated by the current system would have to argue on independent grounds for the necessity of the extra theoretical machinery being introduced. Such attempts would involve lengthy trains of argument whose conclusions would, in all likelihood, be qualified by the proviso that the advisability of the theoretical machinery in question was subject to the validity of certain other theoretical assumptions (which the current system would not necessarily share). ${ }^{40}$ In short, I cannot think of any intrinsic aspect of the current theory that makes a sloppy reading possible for the current example; and, for want of anything else to say, I will have to leave the subject there.

\section{Conclusion}

I conclude, then, that the implicit content associated with incomplete definite descriptions comes in the form of definite descriptions of situations. This is a claim about the semantic type of this content and not a claim about the levels of representation at which this content appears.

We cannot automatically assume that other instances of implicit content (e.g. quantifier domain restriction, weather reports) work similarly, although the possibility is of course raised. Any such claims would have to be argued for on a case-by-case basis. But there are a couple of wider implications of the current work. Schwarzschild's (1999) theory of GIVENness has gained some support from a perhaps unlikely quarter, since it neatly predicts the data used here. And we can conclude that further support is hereby afforded for according an important place in semantics to situations.

\footnotetext{
ular.

${ }^{40}$ See Elbourne 2005, 32 for some sceptical comments on one application of centering theory, in partic-
} 
Acknowledgements Talks based on this paper have been given to the Linguistics and Philosophy Reading Group at University College London, the Semantics, Pragmatics and Philosophy of Language Workshop (June 2015) at the University of Cambridge, and the Faculty of Philosophy at the University of Oxford. I am grateful to everyone who was present on those occasions, and especially (for their contributions) to Bill Child, Annabel Cormack, Lizzie Fricker, John Hawthorne, Minyao Huang, Kasia Jaszczolt, Philipp Koralus, Ofra Magidor, Andrew Nevins, Daniel Rothschild, Yasutada Sudo and Tim Williamson. I am particularly grateful to two anonymous NALS reviewers for their detailed, challenging and thoughtful commentary, and to the editors of Natural Language Semantics.

\section{References}

Armstrong, D. 1978. Universals and Scientific Realism, volume 1: Nominalism and Realism. Cambridge University Press, Cambridge.

Bach, K. 1994. Conversational impliciture. Mind \& Language, 9:124-62.

Berman, S. 1987. Situation-based semantics for adverbs of quantification. In Blevins, J. and Vainikka, A., editors, Studies in Semantics, volume 12 of University of Massachusetts Occasional Papers in Linguistics, pages 46-68. GLSA, Amherst.

Bezuidenhout, A. 1997. Pragmatics, semantic underdetermination, and the referential/attributive distinction. Mind, 106:375-410.

Büring, D. 2004. Crossover situations. Natural Language Semantics, 12:23-62.

Carston, R. 2002. Thoughts and Utterances. Blackwell, Oxford.

Chomsky, N. 1993. A minimalist program for linguistic theory. In Hale, K. and Keyser, S. J., editors, The View from Building 20: Essays in Linguistics in Honor of Sylvain Bromberger, pages 1-52. MIT Press, Cambridge, Mass.

Chomsky, N. 1995. The Minimalist Program. MIT Press, Cambridge, Mass.

Cresswell, M. J. 1990. Entities and Indices. Kluwer, Dordrecht.

Elbourne, P. 2001. E-type anaphora as NP-deletion. Natural Language Semantics, 9(3):241-88.

Elbourne, P. 2005. Situations and Individuals. MIT Press, Cambridge, Mass.

Elbourne, P. 2008. The argument from binding. Philosophical Perspectives, 22:47-68.

Elbourne, P. 2010. On bishop sentences. Natural Language Semantics, 18:65-78.

Elbourne, P. 2013. Definite Descriptions. Oxford University Press, Oxford.

Elbourne, P. Forthcoming. Literal vs. enriched meaning: It's raining. In Matthewson, L., Meier, C., Rullmann, H., and Zimmermann, T. E., editors, Companion to Semantics. Wiley, Malden, Mass.

von Fintel, K. 1994. Restrictions on Quantifier Domains. PhD thesis, University of Massachusetts, Amherst. Fox, D. 2000. Economy and Semantic Interpretation. MIT Press, Cambridge, Mass.

Frege, G. 1891. Function und Begriff: Vortrag, gehalten in der Sitzung vom 9. Januar 1891 der Jenaischen Gesellschaft für Medicin und Naturwissenschaft. Hermann Pohle, Jena.

Frege, G. 1892. Über Sinn und Bedeutung. Zeitschrift für Philosophie und Philosophische Kritik, 100:25-50.

Frey, W. and Gärtner, H.-M. 2002. On the treatment of scrambling and adjunction in minimalist grammars. In Jäger, G., Monachesi, P., Penn, G., and Wintner, S., editors, Proceedings of Formal Grammar 2002, pages 41-52, Trento. FGTrento: The 7th Conference on Formal Grammar.

Geach, P. 1962. Reference and Generality: An Examination of Some Medieval and Modern Theories. Cornell University Press, Ithaca, N.Y.

Grosz, B., Joshi, A., and Weinstein, S. 1995. Centering: A framework for modelling the local coherence of discourse. Computational Linguistics, 21:203-25.

Hall, A. 2008. Free enrichment or hidden indexicals? Mind \& Language, 23:426-56.

Heim, I. 1990. E-type pronouns and donkey anaphora. Linguistics and Philosophy, 13:137-77.

Heim, I. 1993. Anaphora and semantic interpretation: A reinterpretation of Reinhart's approach. Technical report, Seminar für Sprachwissenschaft der Universität Tübingen, Tübingen. SfS-Report-07-93.

Heim, I. and Kratzer, A. 1998. Semantics in Generative Grammar. Blackwell, Oxford.

Hindley, J. R. and Seldin, J. P. 2008. Lambda-Calculus and Combinators: An Introduction. Cambridge University Press, Cambridge.

Keshet, E. 2008. Only the strong: Restricting the situation variables. In Friedman, T. and Ito, S., editors, Proceedings of Semantics and Linguistic Theory XVIII, pages 483-95, Ithaca. Cornell University.

Kratzer, A. 1989. An investigation of the lumps of thought. Linguistics and Philosophy, 12:607-53.

Kratzer, A. 1991. The representation of focus. In von Stechow, A. and Wunderlich, D., editors, Semantik. Ein internationales Handbuch der zeitgenössischen Forschung, pages 825-34. Walter de Gruyter, Berlin.

Kratzer, A. 1996. Severing the internal argument from its verb. In Rooryck, J. and Zaring, L., editors, Phrase Structure and the Lexicon, pages 109-37. Kluwer, Dordrecht.

Kratzer, A. 2004. Covert quantifier restrictions in natural languages. University of Massachusetts, Amherst. 
Kratzer, A. 2014. Situations in natural language semantics. In Zalta, E. N., editor, The Stanford Encyclopedia of Philosophy. CSLI, Stanford University, Stanford, Calif., spring 2014 edition. http: //plato.stanford.edu/archives/spr2014/entries/situations-semantics/.

Kripke, S. 1980. Naming and Necessity. Harvard University Press, Cambridge, Mass.

Kuroda, S.-Y. 1982. Indexed predicate calculus. Journal of Semantics, 1:43-59.

Lanier, W. 2014. Intentional identity and descriptions. Philosophical Studies, 170:289-302.

Lewis, D. 1968. Counterpart theory and quantified modal logic. Journal of Philosophy, 65:113-26.

Michaelis, J. 2001. Derivational minimalism is mildly context-sensitive. In Moortgat, M., editor, Logical Aspects of Computational Linguistics: Third International Conference, LACL '98, Grenoble, France, December 14-16, 1998, Selected Papers, pages 179-198. Springer, Berlin.

Montague, R. 1973. The proper treatment of quantification in ordinary English. In Hintikka, J., Moravcsik, J., and Suppes, P., editors, Approaches to Natural Language: Proceedings of the 1970 Stanford Workshop on Grammar and Semantics, pages 221-42. Reidel, Dordrecht.

Neale, S. 1990. Descriptions. MIT Press, Cambridge, Mass.

Neale, S. 2000. On being explicit: Comments on Stanley and Szabó, and on Bach. Mind \& Language, 15:284-94.

Neale, S. 2004. This, that, and the other. In Reimer, M. and Bezuidenhout, A., editors, Descriptions and Beyond, pages 68-182. Oxford University Press, Oxford.

Neale, S. 2007. Heavy hands, magic, and scene-reading traps. European Journal of Analytic Philosophy, 3(2):77-132.

Peano, G. 1906. Super theorema de Cantor-Bernstein et additione. Rivista de matematica, 8:136-57.

Quine, W. v. O. 1940. Mathematical Logic. Harvard University Press, Cambridge, Mass.

Recanati, F. 1993. Direct Reference. From Language to Thought. Blackwell, Oxford.

Recanati, F. 1996. Domains of discourse. Linguistics and Philosophy, 19:445-75.

Recanati, F. 2004. Literal Meaning. Cambridge University Press, Cambridge.

Recanati, F. 2010. Truth-Conditional Pragmatics. Oxford University Press, Oxford.

Rooth, M. 1992. Ellipsis redundancy and reduction redundancy. In Berman, S. and Hestvik, A., editors, Proceedings of the Stuttgart Ellipsis Workshop, volume 29 of Arbeitspapiere des Sonderforschungsbereichs 340. University of Stuttgart, Stuttgart.

Russell, B. 1905. On denoting. Mind, 14:479-93.

Sauerland, U. and Elbourne, P. 2002. Total reconstruction, PF movement, and derivational order. Linguistic Inquiry, 33(2):283-319.

Schwarz, F. 2009. Two Types of Definites in Natural Language. PhD thesis, University of Massachusetts, Amherst.

Schwarz, F. 2012. Situation pronouns in determiner phrases. Natural Language Semantics, 20:431-75.

Schwarz, F. 2014. Review of Elbourne 2013. Journal of Linguistics, 50:731-38.

Schwarzschild, R. 1999. GIVENness, AvoidF and other constraints on the placement of accent. Natural Language Semantics, 7:141-77.

Selkirk, E. 1995. Sentence prosody: Intonation, stress, and phrasing. In Goldsmith, J., editor, The Handbook of Phonological Theory, pages 550-69. Blackwell, Oxford.

Sellars, W. 1954. Presupposing. Philosophical Review, 63:197-215.

Sperber, D. and Wilson, D. 1986. Relevance: Communication and Cognition. Blackwell, Oxford. Revised second edition in 1995.

Stabler, E. 1997. Derivational minimalism. In Retoré, C., editor, Logical Aspects of Computational Linguistics: First International Conference, LACL '96, Nancy, France, September 1996, Selected Papers, pages 68-95. Springer, Berlin.

Stabler, E. 2011. Computational perspectives on minimalism. In Boeckx, C., editor, Oxford Handbook of Linguistic Minimalism, pages 617-642. Oxford University Press, Oxford.

Stabler, E. 2013. Two models of minimalist, incremental syntactic analysis. Topics in Cognitive Science, 5:611-633.

Stanley, J. 2002. Making it articulated. Mind \& Language, 17:149-68.

Stanley, J. 2005. Semantics in context. In Preyer, G. and Peter, G., editors, Contextualism in Philosophy: Knowledge, Meaning, and Truth, pages 221-53. Oxford University Press, Oxford

Stanley, J. and Szabó, Z. 2000. On quantifier domain restriction. Mind \& Language, 15:219-61.

Strawson, P. 1950. On referring. Mind, 59:320-44.

Strawson, P. 1954. A reply to Mr Sellars. Philosophical Review, 63:216-31.

Strawson, P. 1961. Singular terms and predication. Journal of Philosophy, 58(15):393-412.

Szabó, Z. G. 2000. Descriptions and uniqueness. Philosophical Studies, 101:29-57.

Szabó, Z. G. 2003. Definite descriptions without uniqueness: A reply to Abbott. Philosophical Studies, 114:279-91.

Umbach, C. 2001. (De)accenting definite descriptions. Theoretical Linguistics, 27:251-80. 
Whitehead, A. N. and Russell, B. 1925. Principia Mathematica, volume I. Cambridge University Press, Cambridge, 2nd edition.

Wigner, E. 1960. The unreasonable effectiveness of mathematics in the natural sciences. Communications on Pure and Applied Mathematics, 13(1):1-14. 